Please cite this article in press as: A. Tamburini, A. Cipollina, S. Al-Sharif, M. Albeirutty, L. Gurreri, G. Micale, M. Ciofalo (2014): Assessment of temperature polarization in membrane distillation channels by liquid crystal thermography, Desalination and Water Treatment, DOI: 10.1080/19443994.2014.957916

\title{
ASSESMENT OF TEMPERATURE POLARIZATION IN MEMBRANE DISTILLATION CHANNELS BY LIQUID CRYSTAL THERMOGRAPHY
}

\author{
A. Tamburinia ${ }^{a}$, A. Cipollina ${ }^{a *}$, S. Al-Sharif ${ }^{b}$, M. Albeirrutty ${ }^{b}$ L. Gurreria ${ }^{a}$, G. Micale ${ }^{a}$, M.
}

Ciofalo $^{\mathbf{a}}$

${ }^{a}$ Dipartimento di Ingegneria Chimica, Gestionale, Informatica, Meccanica (DICGIM), Università di Palermo (UNIPA) - viale delle Scienze Ed.6, 90128 Palermo, Italy

${ }^{b}$ Center of Excellence in Desalination Technology, King Abdullaziz University, PO Box 80200, Jeddah 21589, Saudi Arabia

* Corresponding author: andrea.cipollina@unipa.it

\begin{abstract}
The measurement of local temperature distributions within a Membrane Distillation (MD) channel is a crucial step for the optimization of the channel and spacer geometry. This information allows the estimation of temperature polarization phenomena, which can dramatically influence the thermal efficiency of the process and the optimal choice of the geometric configuration (net spacer features, channel size, etc.). In the present work a recently presented experimental technique, based on the use of Thermochromic Liquid Crystals (TLCs) and digital image analysis, has been employed in order to assess temperature polarization phenomena. The local heat transfer coefficient distribution on the membrane surface in a MD spacer-filled channel
\end{abstract}


was thus assessed. Different diamond spacers geometries were investigated, in order to highlight how the geometrical features affect both pressure drop and heat transfer in spacer filled channels.

Key words: Membrane Distillation; Thermochromic Liquid Crystals; Heat Transfer; Temperature Polarization; Digital Image Analysis.

\section{INTRODUCTION}

The process of membrane distillation has attracted much attention in the last decades [1]. Owing to a number of interesting features, it has the potential of providing a sustainable desalination solution on small to medium scales, or to extend the overall productivity of a desalination plant when coupled with existing technologies. The main attractive feature is the type of energy that is needed to drive the process, namely low grade thermal energy [2]. This means that it is a potentially attractive candidate for pairing with thermal renewable energy sources, such as solar or geothermal energy, and/or taking advantage of waste heat, where any of these are available [3-10].

As the name suggests, the process is based on distillation, but in this case the distillation is achieved without actually boiling the saline feed water, as in conventional thermal desalination systems such as Multi Stage Flash and Multi Effect Distillation. Rather, a negative vapour pressure gradient is simply maintained between two sides of a microporous hydrophobic membrane, causing a net flux of vapour, from the warm saline feed side to the cooler permeate side [11]. The vapour transported through the pores of the hydrophobic membrane is then condensed, either directly onto a cooler stream on the permeate side, or on a separate internal or external condensation surface. Achieving distillation without boiling means that the feed water does not have to be maintained at saturation conditions, which simplifies the mechanical construction of the system since there need not be any significant differential pressure on the vessel walls. Moreover, the use of polymeric membranes means that, at least in principle, the construction materials can be more economical than the highquality metals used in conventional thermal desalination systems. Another major feature of MD is 
that the specific energy required by the process does not quickly rise with the salinity of the feed as it occurs, for example, in the case of reverse osmosis [12]. This allows MD to be applied to desalinate very high salinity feed waters, and opens up a wide range of synergistic opportunities for hybrid technology applications.

In principle, the process can operate with a very small vapour pressure (and thus, temperature) difference, but small driving forces lead to small fluxes, which means that a large membrane surface area would be needed for a given production capacity. More significant, however, is the fact that not all of the applied temperature difference becomes utilised as a driving force. The reason is that, with fluids flowing on both sides of the membrane, the trans-membrane temperature difference is invariably lower than the difference between the bulk temperatures of the respective fluid streams. This temperature polarization effect is the result of convective heat transfer resistances on both sides and it is usually quantified by the temperature polarization coefficient, defined as the ratio between the trans-membrane temperature difference and the difference between the bulk temperatures of the two streams (feed and permeate).

Poor control over temperature polarization will prevent the process from delivering the output that would potentially be possible on the basis of the temperature difference between hot and cold stream $[13,14]$. The amount of temperature polarization is determined by the balance between convective heat fluxes, which are governed by hydrodynamic conditions, and the heat flux through the membrane, which is governed by the vapour mass flux. Thus, larger trans-membrane vapour fluxes need to be matched by higher convective heat transfer coefficient if polarization is to be controlled. With much research effort currently directed towards improved membranes, tailored specifically for MD to yield increasingly higher vapour fluxes, temperature polarization may become the main limiting factor for performance if the issue of module hydrodynamics is not carefully addressed.

The principal means by which polarization, of all kinds, is controlled within flat membrane configurations (including plate $\&$ frame and spiral wound modules) is the use of channel spacers. 
These typically consist of a net of polymeric filaments of varying geometrical features, such as the diameter of the filaments and the angle and spacing between them, among other features. Spacers play an important role in promoting mixing and in guaranteeing the dimensional stability of the channel. Clearly, mixing promotion allows polarization phenomena at a given flow rate (Reynolds number) to be significantly reduced. On the other hand, spacers exhibit the disadvantage of causing hydraulic losses to increase $[15,16]$.

One of the first important studies devoted to the investigation of spacer-filled channels is by Schock and Miquel [16], who collected experimental data on pressure drop and mass transfer characteristics for the case of spiral wound units. Correlations concerning the dependence of the friction factor and the Sherwood number $(S h)$ on the Reynolds number $(R e)$ were proposed, and a performance calculation aiming at the optimization of spiral wound elements was addressed. Da Costa et al. [15] performed a more detailed analysis of spacer characteristics and presented more general correlations. In the last decades, many other research efforts have been devoted to a thorough overall understanding of the effect of spacer geometry (filament spacing, filament diameter, filament shape, angle between crossing filaments, flow attack angle) on fluid dynamics features (flow pattern, recirculation, shear rate distribution, flow regime, pressure drops) and mass transfer phenomena within the channel [17-40].

In particular for the case of the MD application, Velázquez and Mengual [41]carried out experiments to evaluate the temperature polarization coefficient in spacer-filled channels. MartínezDiez and Rodríguez-Maroto [42] introduced the vapour pressure polarization coefficient in order to measure the reduction in the effective driving force for mass transport. However, temperature polarization was proved to be more important than concentration polarization in their MD experiments, as confirmed later by Laganà et al. [43]. Martinez et al. [44] and Yun et al. [45] stated that coarser spacers with thicker filaments perform better in reducing polarization and enhancing mass flux. In this regard, Phattaranawik et al. [46] found flux enhancement up to $41 \%$ in spacerfilled channels compared to the empty channel. Such enhancements were also confirmed by the 
application of the Da Costa et al. [15] correlation to the MD case on the basis of the analogy between heat and mass transfer. The same authors ([47]) tested a number of existing correlations for laminar and turbulent flow conditions finding that: (i) the effects of mass transfer on heat transfer rates can be neglected, and (ii) the significance of heat conduction in the membranes and of heat transfer due to the vapour flow was comparable. Following such findings, the same authors ([48]) refused the adoption of the analogy between heat and mass transfer and proposed a new correlation more suitable to the case of MD. Chernyshov et al. [49] experimentally investigated the effect of spacer geometry on process performance for the case of air gap membrane distillation: when a spacer was employed within the channel, a mass flux up to 2.5 times higher than in a spacerless channel was found. However, due to the relevant pressure drop increase, the spacerless channel was found to provide the highest flux at a given pressure drop. A model to characterize a direct contact membrane distillation module was developed by Martínez and Rodríguez-Maroto [50], aiming at determining the mass and heat transfer coefficients through the membrane and the boundary layers. Significant heat transfer improvements were found by the authors in the spacer-filled channel (>50\%) both by the model and by experiments.

Currently the selection of channel spacers within the context of membrane distillation is often based on what is already available commercially, rather than being based on detailed hydrodynamic considerations or on a customised design. Given the important role that channel spacers are meant to play in controlling the detrimental effect of temperature polarization, there is a definite need for rational experimentally based methodologies for spacer selection. Ideally, the desired methodology would provide local spatial resolution, revealing the detailed hydrodynamic and heat transfer features of a candidate spacer. This aspect is available in computational fluid dynamics (CFD), which, in principle, can provide complete detail of all features of the fluid flow and heat transfer. Indeed there have been several studies applying CFD to spacer-filled channels for MD [51-55], and these have generally demonstrated the great deal of useful and relevant information that can be extracted from CFD simulations. What is lacking at this point is thorough experimental validation. 
This is mainly because the available experimental techniques are mostly able to provide measurements of spatially averaged quantities and at best $1 \mathrm{D}$ variations.

One example found in the literature of measurements of local quantities is by Ali et al. [56]. They analysed heat and mass transfer in direct contact membrane distillation (MD) by using a cell equipped with sixteen sensors in order to measure the bulk and membrane surface temperatures. A more comprehensive characterization of spacers' behaviour would require a technique able to obtain the distribution of temperature with a higher spatial resolution.

The technique employed in the present work has been presented in previous papers [57, 58]. It addresses the requirement of a high spatial resolution of the temperature field through the use of liquid crystal thermography along with digital image analysis. Image analysis is a cheap way to get information ([59]) which can be employed as a valuable benchmark for CFD model validation ([60]). The technique is described briefly in the next sections; more details can be found in the papers cited above.

\section{EXPERIMENTAL SETUP AND TECHNIQUE FUNDAMENTALS}

The heart of the present measurement technique, firstly applied to MD by Tamburini et al. [58], is liquid crystal thermography. Thermochromic liquid crystals (TLC) are organic substances whose colour varies with temperature. They have a molecular structure that causes them to exhibit selective reflection of visible light based on their temperature ([61]). Commercially available TLCs can come in various forms, such as spray paints and flat strips. In the present technique, flat strips of TLC sheets are used to measure the local surface temperature distribution in a specific controlled region.

Before the TLC strips can be used for temperature measurements they need to be calibrated to determine the exact colour to temperature relationship (more specifically, the hue-temperature relationship). Although modern digital cameras usually output images in the RGB (red, green, blue) colour space, it is more convenient to transform the images into the HSV (hue, saturation, value) 
colour space representation. In this way one needs to deal only with a single quantity, the hue, in the colour-to-temperature transformation, rather than having to deal with three quantities (each of the 3 RGB components). The calibration (see section 2.2) is performed using the same test rig in which the intended experimental measurements are carried out. Details an all these information are provided in the following sections.

\subsection{Experimental setup}

The experimental test section is schematically depicted in Figure 1. It consists of two rectangular flow passages delimited by two thick transparent Plexiglas ${ }^{\circledR}$ plates (which provide structural stiffness and thermal insulation) and a thin transparent polycarbonate sheet. The height of the two flow passages is determined by either the spacer to be tested (hot channel) or by the appropriately sized gaskets (cold channel). The warmer water flows in the bottom channel (hot channel), where the spacer to be tested is placed. One or several adhesive-backed TLC strips (manufactured by Hallcrest ${ }^{\circledR}$ ) are affixed to the polycarbonate sheet on the side of the hot channel, in contact with the spacer tested. The cooling water flows in the top channel, and since no visual obstruction between the TLC strip and the camera is desired, no spacer is used in the cold channel. 


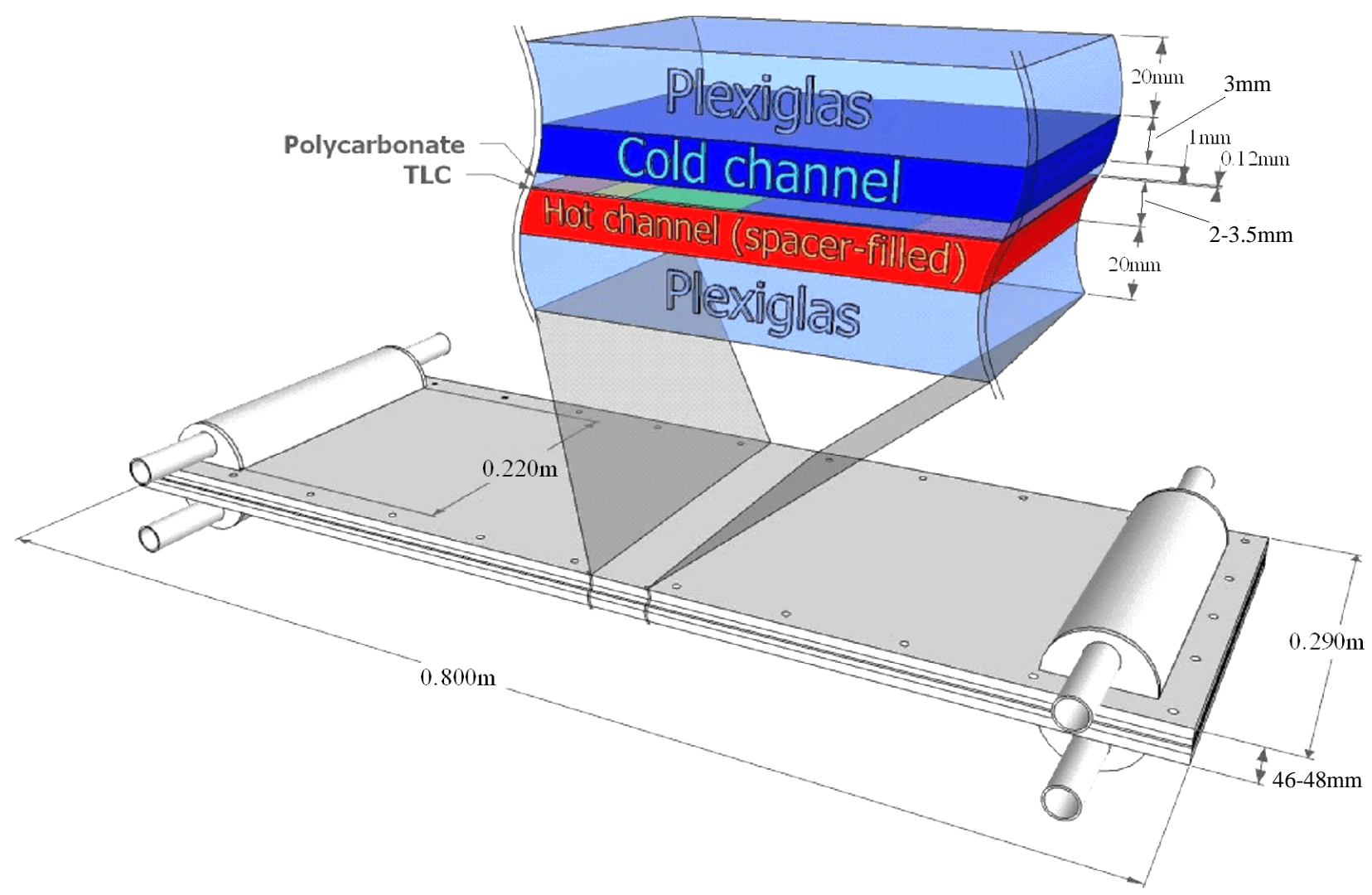

Figure 1: Sketch of the test section along with the indication of the different layers

There are two pressure taps along the flow (axial) direction of the bottom channel, which are connected either to a differential pressure transducer (Fuji Electric FCX-AII Series) or an inclinedtube manometer, thus allowing pressure drops to be measured. The Plexiglas ${ }^{\circledR}$ test section is fixed in place on an aluminium frame structure, which also supports a digital camera (Canon ${ }^{\circledR}$ EOS 550 D) and two light sources at the top, as depicted in Figure 2. 


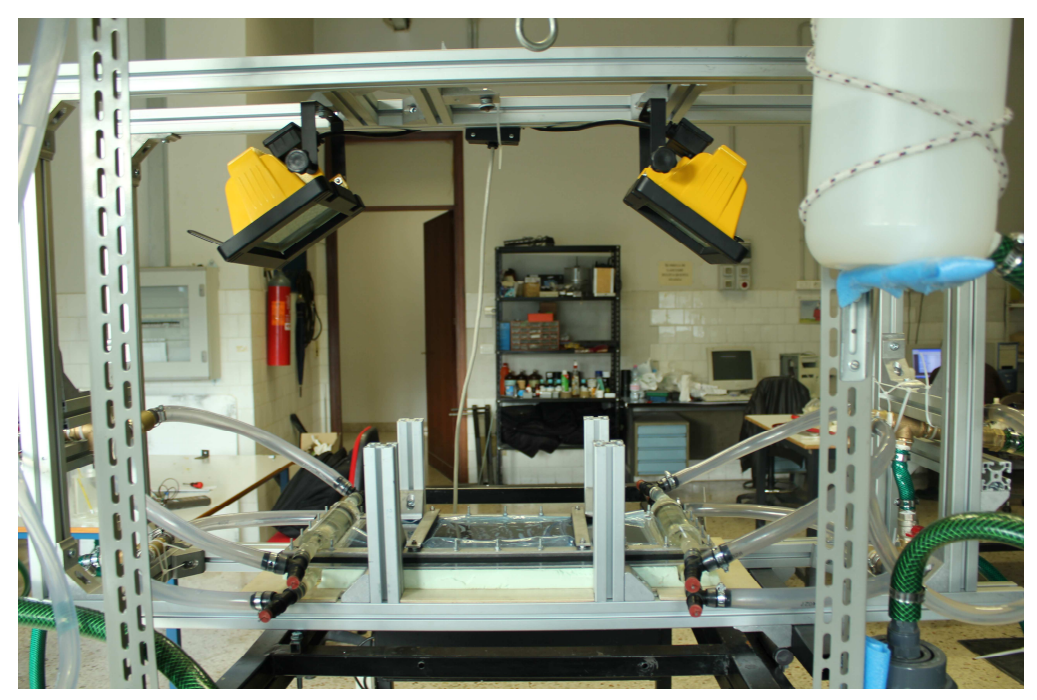

Figure 2: Picture of the experimental rig

A chiller $\left(\right.$ Corema $^{\circledR}$ Junior Chiller JA/C 150) and a thermostatic heating bath (Julabo ${ }^{\circledR}$ ED-5) are used to control the temperatures of the cold and warm flows, respectively. The desired flow rates are supplied by two recirculation pumps with flow control valves, and the two flow rates are measured using magnetic flow meters (Krohne ${ }^{\circledR}$ Optiflux $\left.5300 \mathrm{C}\right)$. The inlet and outlet temperatures of both flows are measured using four Pt100 probes, which transmit their readings to a data acquisition system (National Instruments ${ }^{\circledR}$ ).

\subsection{TLC calibration procedure}

As already anticipated, the colour information provided by TLC images can be converted into a temperature distribution only by a suitable calibration of the liquid crystals. The thermochromic response of the TLC sheet used was characterized by an in-situ calibration performed according to the steady-state method of uniform surface temperature ([62]).

Water coming from the heating circulator was forced to flow through the channels on both sides of the TLC-polycarbonate wall and its temperature was progressively increased from $30^{\circ} \mathrm{C}$ up to $42^{\circ} \mathrm{C}$ in $0.2^{\circ} \mathrm{C}$ steps. For each imposed temperature, once steady state conditions were achieved in the module, a photograph of the colorimetric response of the TLCs was acquired thus resulting into the 
hue vs temperature (H-T) data shown in Figure 3. A 9th degree polynomial was employed to fit the data and provide the calibration curve. Of course, all experiments were carried out at temperatures falling within the useful range of calibration and in particular in the interval $35-40{ }^{\circ} \mathrm{C}$.

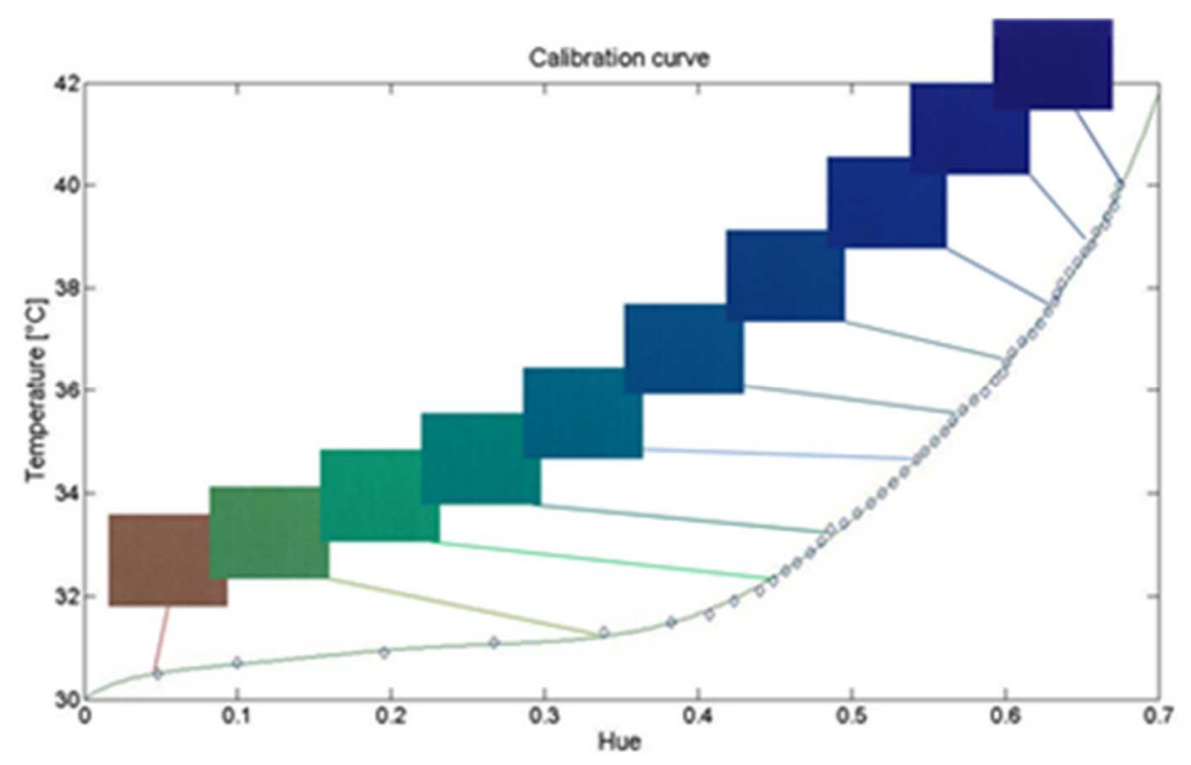

Figure 3: Hue vs Temperature calibration curve

\subsection{Experimental measurement procedure}

In order to perform a measurement, the spacer to be tested is placed in position in the bottom channel and the Plexiglas ${ }^{\circledR}$ test section is carefully sealed. The section is then placed in position and connected to the water circulation loops. The desired inlet temperatures are set and the flow rates are gradually brought to the desired level. Care is taken to remove trapped air bubbles from the two flow loops, and the system is left to reach a steady state. At this point, the light sources (with which the TLC strips were calibrated) are switched on, and other light sources in the lab are turned off or blocked. A series of digital images is then captured and recorded, while simultaneously recording the inlet and outlet temperatures using the DAQ system. The differential pressure between the two pressure taps is also recorded. All the images collected are then processed by using the $\mathrm{Matlab}^{\circledR}$ Image Processing Toolbox. TLC images, acquired by the camera in a RAW format for maximum 
quality, are first converted into the TIFF format so that they could be processed in Matlab ${ }^{\circledR}$. Here, as anticipated, they are converted from RGB (red, green, blue) to HSL (hue, saturation, lightness) components. The calibration curve provides the relationship between hue and temperature thus allowing Hue data to be converted into temperature data.

If the bulk temperatures of both fluids and the cold side heat transfer coefficient $h_{c}$ are known, the hot-side heat transfer coefficient $h_{h}$ can be inferred from the temperature $T_{1}$ of the TLC sheet. With reference to the temperature profiles outlined in Figure 4 (which also reports the relevant nomenclature), by assuming one-dimensional heat transfer, $\mathrm{h}_{\mathrm{h}}$ can be computed as follows:

$$
h_{h}=\frac{T_{1}-T_{c}}{\left(T_{h}-T_{1}\right)\left(\frac{L_{T L C}}{k_{T L C}}+\frac{L_{p}}{k_{p}}+\frac{1}{h_{c}}\right)}
$$

The soundness of the one-dimensional transfer hypothesis was already demonstrated in a previous Work ([58]).

Although eq. (1) contains the (unknown) cold-side heat transfer coefficient $h_{c}$, it was verified that, provided $h_{c} \gg h_{h}$, the computed value of $h_{h}$ is little sensitive to the value of $h_{c}$. Therefore, this last value was simply computed by the Dittus-Boelter heat transfer correlation on the basis of the cold channel thickness and cold fluid flow rate.

Distributions of local temperature and heat transfer coefficient over the hot side of the dividing polycarbonate were thus obtained for each of the test conditions described in the following section 2.4. The analysis of the results allowed the identification of the spacer's geometrical features which locally enhance heat transfer and reduce T-polarization. The experimental data allowed also mean heat transfer coefficients and friction coefficients to be obtained for the whole range of geometrical configurations and flow rates investigated. 


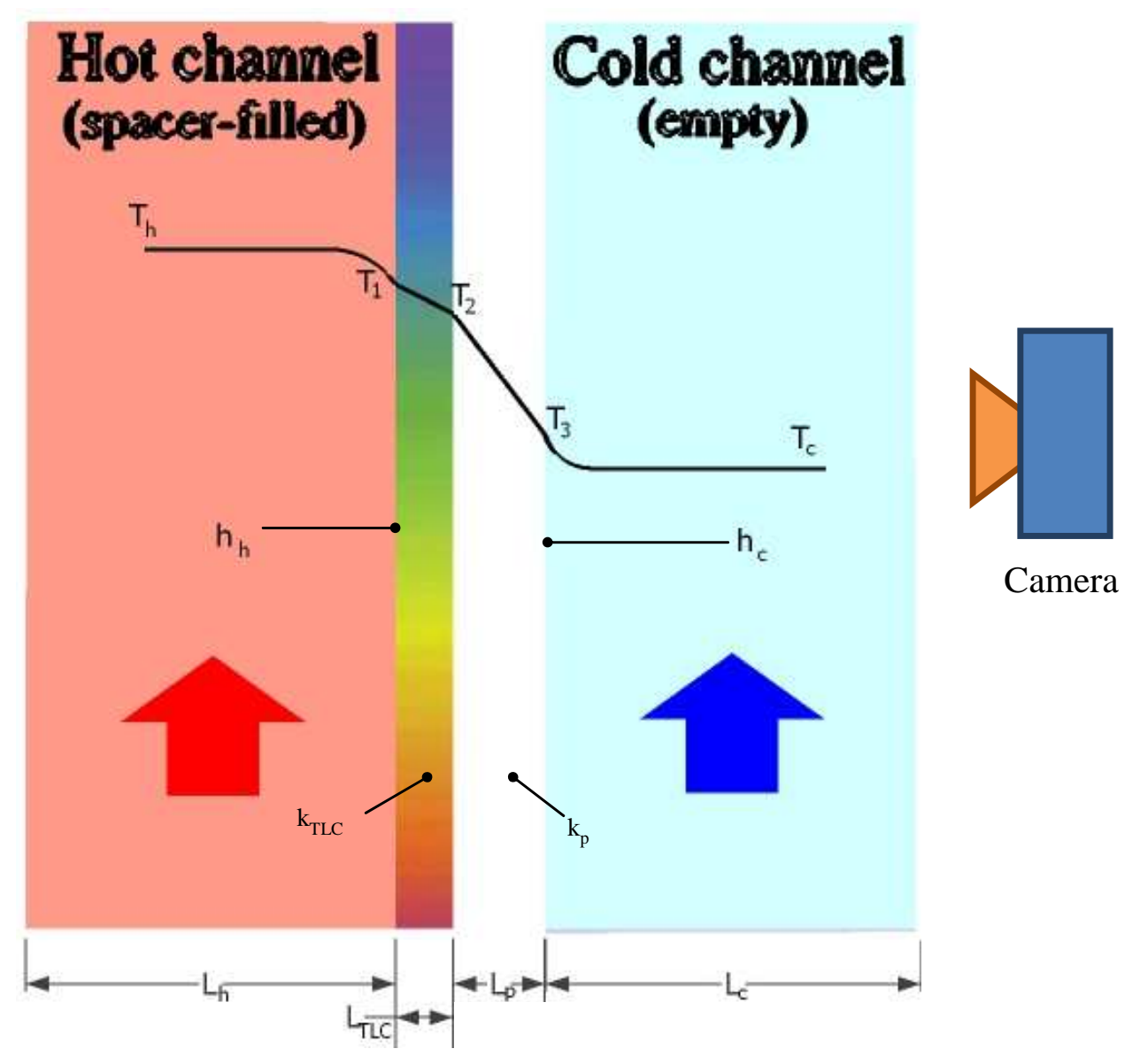

Figure 4: Temperature profile on a hypothetical line orthogonal to the TLC sheet

\subsection{Test conditions investigated}

The geometrical parameters describing each spacer are sketched in Figure 5.

Three different spacers were investigated and for two of them different orientations with respect to the main flow direction were tested. The main features of these spacers in are reported in Table 1 where the porosity $\varepsilon$ is also reported. From elementary geometric considerations it can be computed as:

$\mathcal{E}=1-\frac{\pi\left(d_{f 1}^{2} l_{m 2}+d_{f 2}^{2} l_{m 1}\right)}{4 l_{m 1} l_{m 2} h_{s p} \sin \theta}$ 


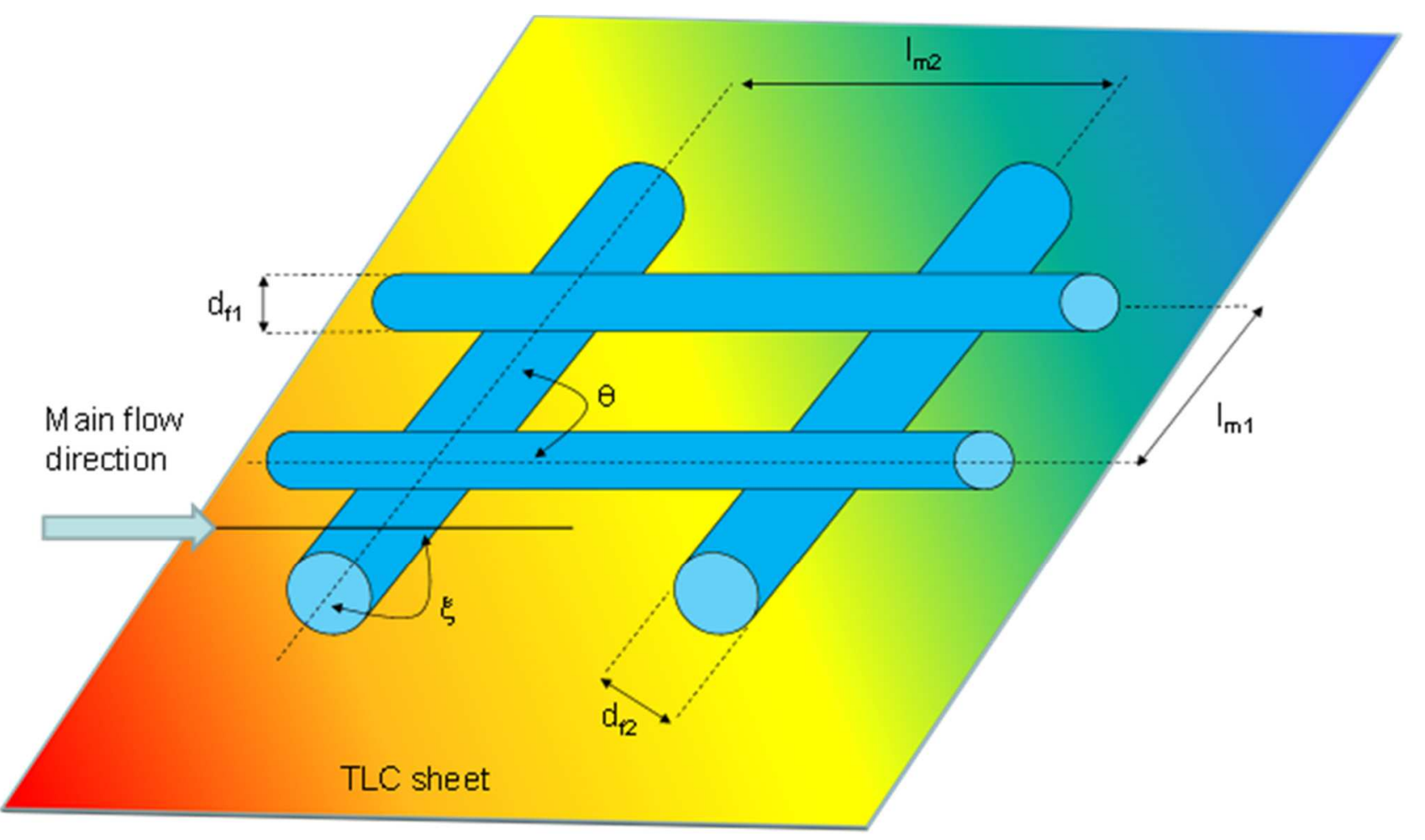

Figure 5: Sketch of a generic spacer along with the TLC sheet.

Different flow rates were investigated for each spacer-filled channel configuration. Such flow rates correspond to Reynolds number ranging from $\approx 100$ to $\approx 2000$. The Reynolds number was calculated in accordance with the definition by Schock and Miquel [16]:

$\operatorname{Re}=\frac{\rho u_{v o i d} d_{h, v o i d}}{\mu}$

where $\rho$ is density, $\mu$ is viscosity, $\mathrm{u}_{\text {void }}$ is the average velocity along the main flow direction in a corresponding spacerless channel, and $\mathrm{d}_{\mathrm{h}, \text { void }}$ is the hydraulic diameter of the corresponding spacerless channel, conventionally assumed to be equal to twice the channel thickness $h_{\text {sp }}$ (which, in its turn, is equal to the spacer height). The mutual orientation between the flow and the spacer is indicated by the angle $\xi$, defined as the smaller of the two angles formed by the main flow direction with the axis of a filament touching the TLC sheet. 
Table 1: Investigated spacer features (nomenclature in Figure 5)

\begin{tabular}{|c|c|c|c|c|c|c|c|c|c|c|c|}
\hline \multicolumn{3}{|c|}{ Spacer } & \multirow{2}{*}{$\begin{array}{c}\mathbf{h}_{\mathbf{s p}} \\
{[\mathrm{mm}]}\end{array}$} & \multirow{2}{*}{$\boldsymbol{\theta}\left[{ }^{\circ}\right]$} & \multirow{2}{*}{$\begin{array}{c}\xi \\
{\left[{ }^{\circ}\right]}\end{array}$} & \multirow{2}{*}{$\begin{array}{l}\mathbf{d}_{\mathbf{h}, \text { void }} \\
{[\mathrm{mm}]}\end{array}$} & \multirow{2}{*}{$\begin{array}{c}\boldsymbol{\varepsilon} \\
{[-]}\end{array}$} & \multirow{2}{*}{$\begin{array}{c}\mathbf{d}_{\mathbf{f} 1} \\
{[\mathrm{~mm}]}\end{array}$} & \multirow{2}{*}{$\begin{array}{c}\mathbf{d}_{\mathbf{2} 2} \\
{[\mathrm{~mm}]}\end{array}$} & \multirow{2}{*}{$\begin{array}{c}\text { lm1 } \\
{[\mathrm{mm}]}\end{array}$} & \multirow{2}{*}{$\begin{array}{c}\mathrm{lm2} \\
{[\mathrm{mm}]}\end{array}$} \\
\hline Name & Supplier & Code & & & & & & & & & \\
\hline Diamond_1 & \multirow{3}{*}{ Polynet } & \multirow{3}{*}{0126} & 3.5 & 85 & $\sim 45$ & 6.9 & 0.73 & 2.2 & 2 & 7.4 & 7.5 \\
\hline Diamond_2 & & & 3.5 & 85 & $\sim 90$ & 6.9 & 0.73 & 2.2 & 2 & 7.4 & 7.5 \\
\hline Diamond_3 & & & 3.5 & 85 & $\sim 0$ & 6.9 & 0.73 & 2.2 & 2 & 7.4 & 7.5 \\
\hline Diamond 1s & Delstar & 114878 & 2 & 88.5 .5 & $\sim 45$ & 3.97 & 0.86 & 1 & 1 & 5.4 & 5.8 \\
\hline Diamond_30s & \multirow{2}{*}{ Delstar } & \multirow{2}{*}{113796} & 2 & 60 & $\sim 30$ & 3.97 & 0.81 & 1 & 1 & 4.8 & 4.8 \\
\hline Diamond_60s & & & 2 & 60 & $\sim \sim 60$ & 3.97 & 0.81 & 1 & 1 & 4.8 & 4.8 \\
\hline
\end{tabular}

\section{RESULTS AND DISCUSSION}

The TLC-IA-TP technique allows local data on heat transfer features to be assessed. Such local information is provided in the following section 3.1, while the results based on averaged data are reported in section 3.2 .

\subsection{Distributions of temperature, heat transfer coefficient and temperature polarization coefficients}

\subsubsection{Polynet Diamond spacer}

An example of local information which can be obtained by the present technique is reported in Figure 6 for the case of the Diamond_1 configuration $\left(\xi=45^{\circ}\right.$, i.e. flow directed along the bisector of the diamond): Figure 6a,b show a photograph of the spacer and a snapshot of the test section including the TLC, respectively, along with the indication of the main flow direction. Figure $6 \mathrm{c}, \mathrm{d}$ show temperature and heat transfer coefficient distributions, respectively. Two different coefficients were defined to quantify temperature polarization: one is the temperature polarization coefficient (TPC), 
$T P C=\frac{T_{1}-T_{c}}{T_{h}-T_{c}}$

the other is an efficiency loss coefficient $\tau$ defined as

$\tau=1-T P C=\frac{T_{h}-T_{1}}{T_{h}-T_{c}}$

The local distribution of these two coefficients is reported in Figure 6e,f. Notably, since (i) it is not possible to measure the value of $\mathrm{T}_{3}$ and (ii) the flow rate in the cold channel is always kept very high, the temperature polarization in the cold channel was not taken into account in the definition of TPC, which, therefore, is a one-sided polarization coefficient.

As it can be seen in Figure 7c,d, zones with a low wall temperature and corresponding low heat transfer coefficient can be recognized just where the spacer wires are in contact with the TLC surface. In these zones heat transfer is purely conductive thus resulting in the lowest TPC values and in the highest $\tau$ values (Figure 7e,f).

Zones with intermediate heat transfer coefficient can be observed downstream of the spacer wires: here convective transport is poor, presumably because these zones correspond to recirculation regions where the fluid vein remains detached. Conversely, immediately upstream of the filaments, reattachment of the fluid vein occurs and fluid mixing is enhanced thus resulting in higher heat transfer coefficients and lower $\tau$. 


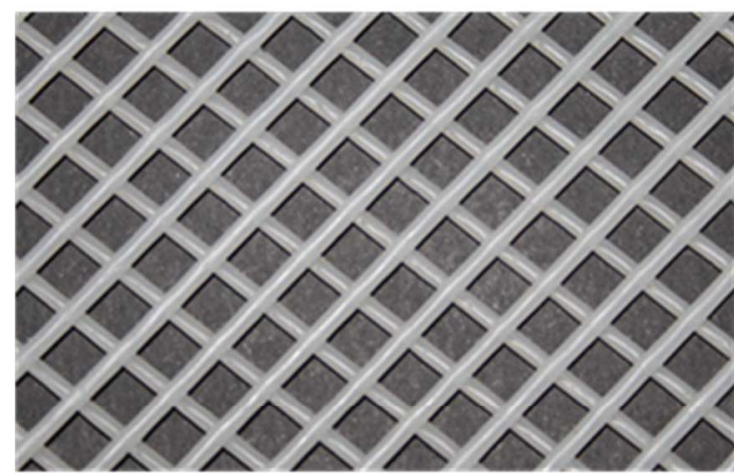

(a)

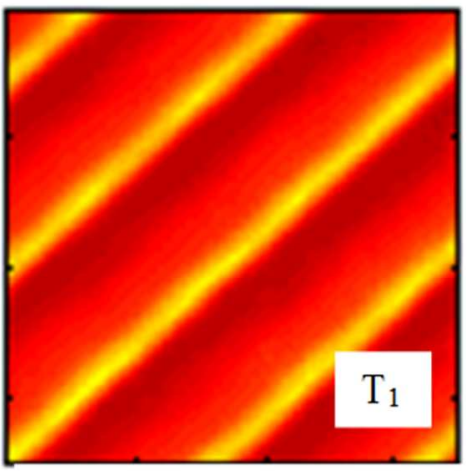

(c)

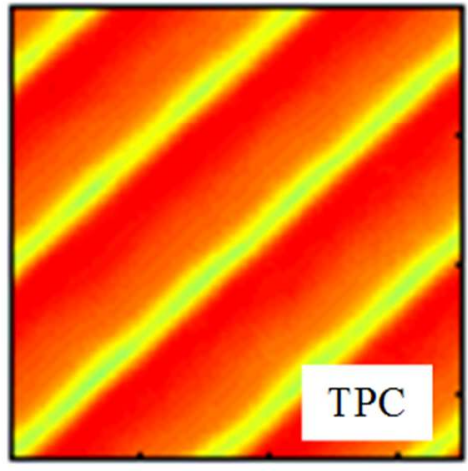

(e)
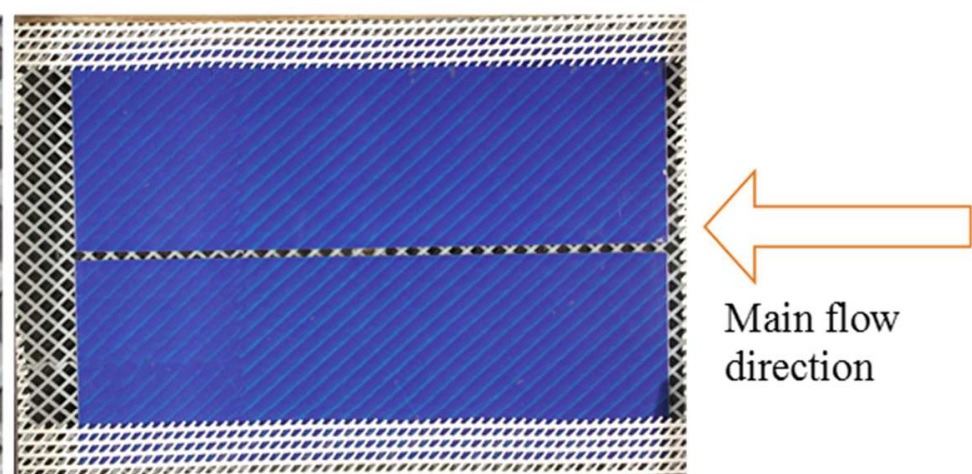

Main flow direction (b)

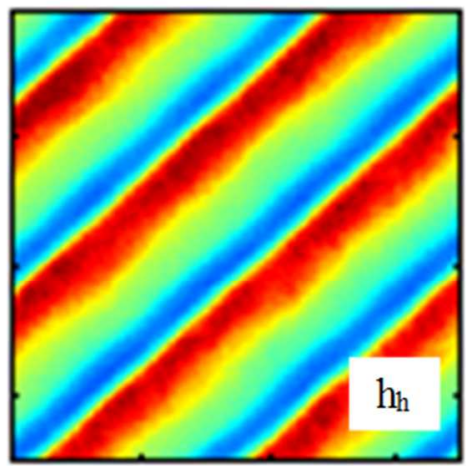

(d)

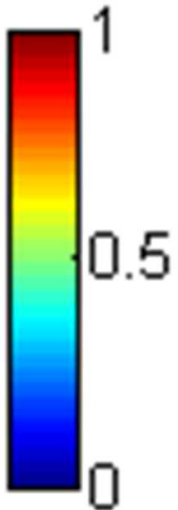

(f)
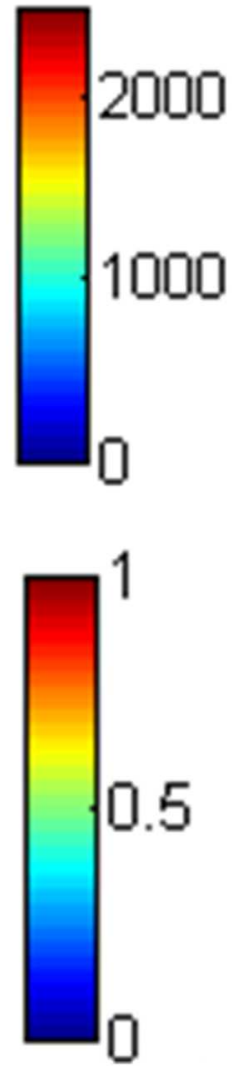

Figure 6: Diamond_1 configuration at high flow rate: (a) Polynet Diamond spacer orientation; (b) acquired snapshot; (c) Temperature distribution colour map $\left[{ }^{\circ} \mathrm{C}\right]$; (d) Heat transfer coefficient distribution colour map $\left[\mathrm{W} \mathrm{m}^{-2} \mathrm{~K}^{-1}\right]$; (e) Temperature Polarization Coefficient colour map [-]; (f) efficiency loss coefficient colour map [-]. $\mathrm{Q}_{\mathrm{h}}=170 \mathrm{1} / \mathrm{h}(\mathrm{Re}=590)$; $\mathrm{T}_{\mathrm{h} \_ \text {mean }}=40.4{ }^{\circ} \mathrm{C}$; $\mathrm{T}_{\mathrm{c} \_ \text {mean }}=22.1^{\circ} \mathrm{C}$.

A slightly different behaviour can be observed for the same spacer at lower flow rate (see Figure 7): the three zones mentioned before can be recognized also in this case, but now they are less defined. This is due to the fact that at low flow rates the fluid acquires a significant velocity component along the wire direction (inclination of $\sim 45^{\circ}$ ) rather than moving only longitudinally. In the former case there is a scarce mixing between the fluid located in the upper layer of filaments and the one 
located in the lower one; conversely, when the fluid flow rate is increased the fluid starts moving up and down thus enhancing mixing and leading the value of the heat transfer coefficient to increase.

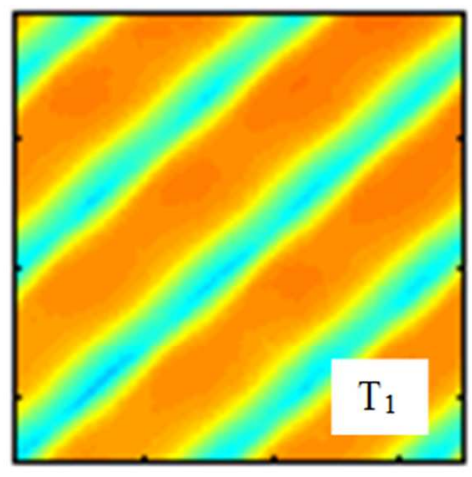

(a)

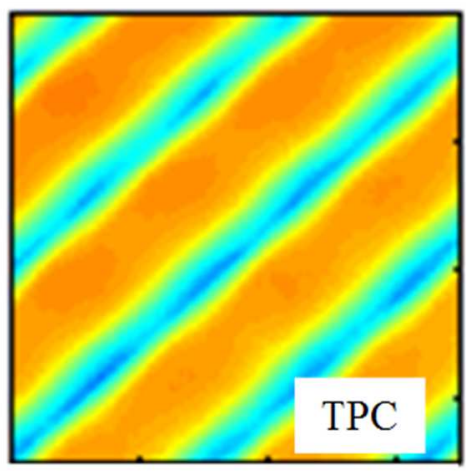

(c)
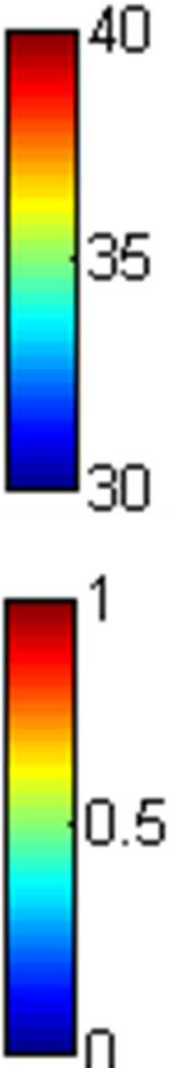

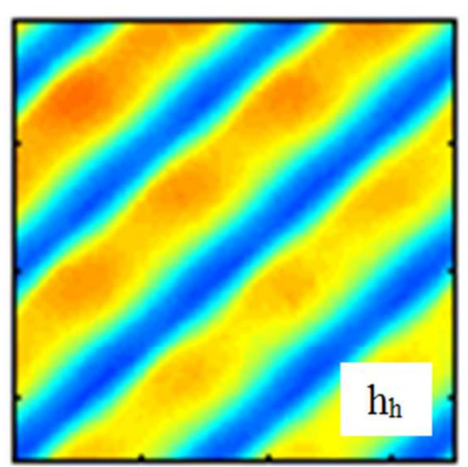

(b)

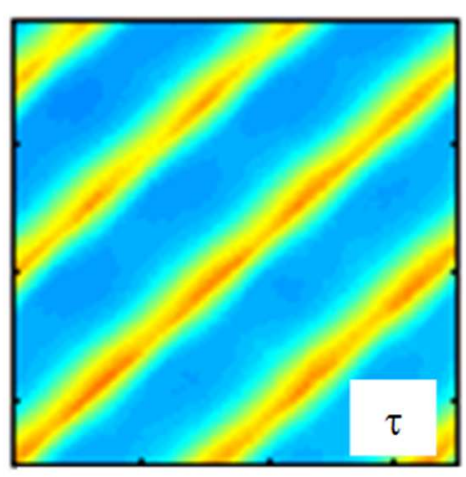

(d)
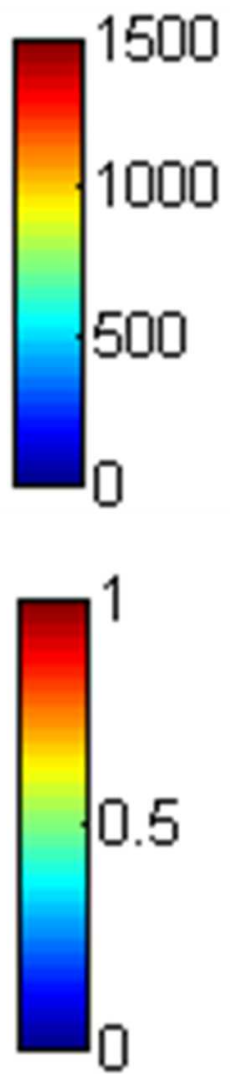

Figure 7: Diamond_1 configuration at low flow rate: (a) Temperature distribution colour map [ $\left.{ }^{\circ} \mathrm{C}\right]$; (b) Heat transfer coefficient distribution colour map [W m ${ }^{-2} \mathrm{~K}^{-1}$ ]; (c) Temperature Polarization Coefficient colour map [-]; (d) efficiency loss coefficient colour $\operatorname{map}[-] . \mathrm{Q}_{\mathrm{h}}=40 \mathrm{l} / \mathrm{h}(\mathrm{Re}=135) ; \mathrm{T}_{\mathrm{h} \_ \text {mean }}=39.4{ }^{\circ} \mathrm{C} ; \mathrm{T}_{\mathrm{c} \_ \text {mean }}=22.1{ }^{\circ} \mathrm{C}$.

In order to confirm this hypothesis, the fluid behaviour at the two different flow rates was investigated via a visual experiment carried out by injecting some ink into the test section (Figure 8). As expected, at the low flow rate, the ink moves preferentially along the spacer wire, while at the high flow rate, the ink moves more longitudinally which leads to a much larger dispersion degree. 

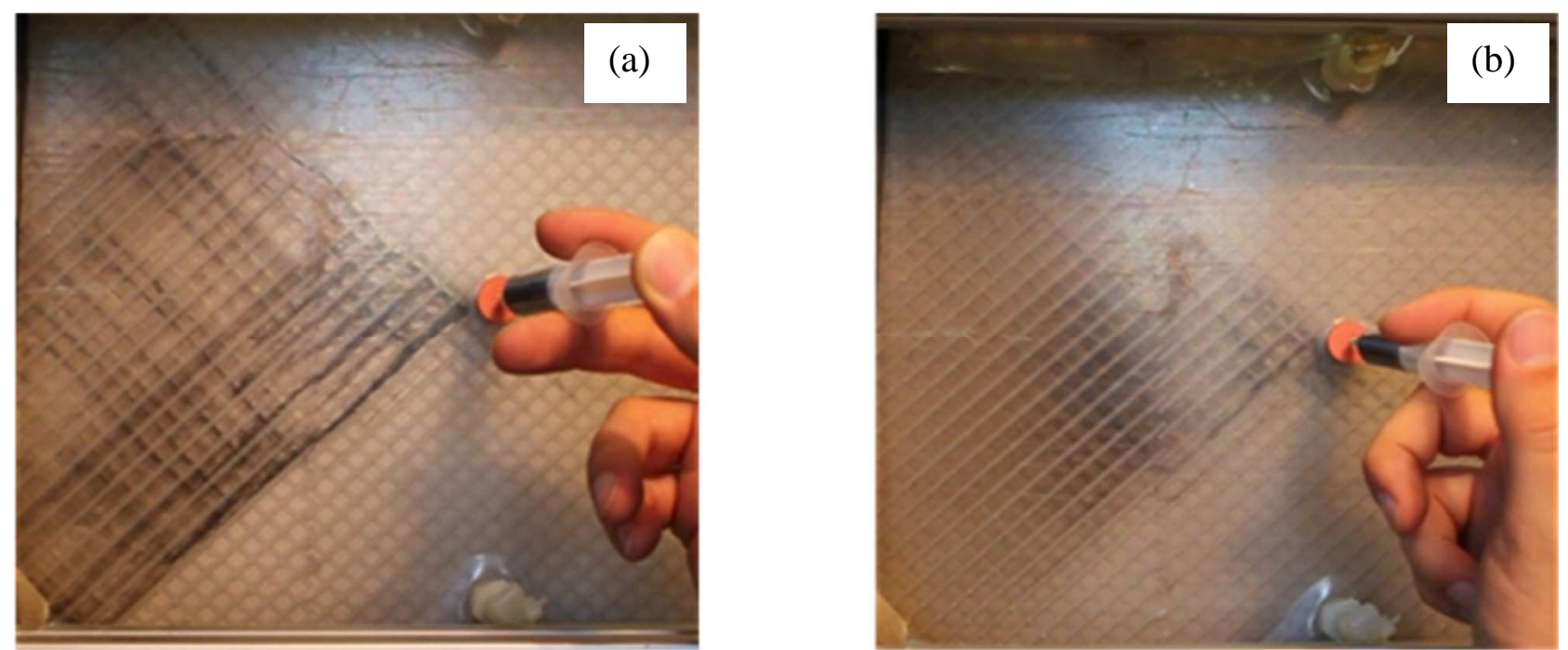

Figure 8: Snapshots of the test section during the injection of some ink at two different flow rates: (a) $\operatorname{Re}=135,(b) \operatorname{Re}=590$.

Notably, in both cases the presence of the filament layer not in contact with the TLC surface does not appear to significantly affect the temperature distribution field on the TLC surface: a very small effect can be observed only at the lower flow rates.

As already reported for the case of the Diamond_1 configuration, also for the Diamond_2 configuration $\left(\xi=90^{\circ}\right.$, i.e. flow orthogonal to the filaments in contact with the active wall) three different zones can be identified as shown in Figure 9: a low heat transfer region where the spacer wires touch the TLC sheet, an intermediate heat transfer region downstream of the filaments where fluid velocity is low due to detachment of the fluid vein, and a high heat transfer region immediately upstream of the filaments where the fluid hits the filament and the fluid vein reattaches thus promoting mixing. As a difference from the Diamond_1 configuration performance at a similar flow rate (see Figure 6), in this case lower $h_{h}$ and TPC were found thus suggesting that the symmetric $\sim 45^{\circ}$ spacer orientation (Diamond_1 configuration) could be more efficient than the $\sim 90^{\circ}$ one (Diamond_2 configuration). 


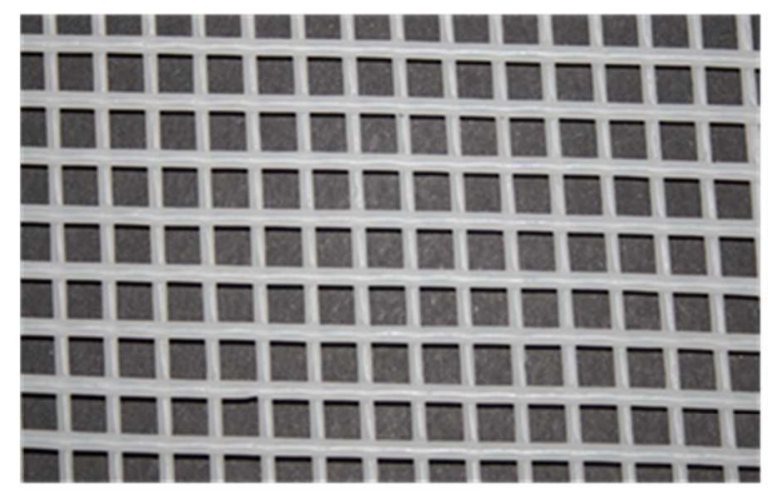

(a)

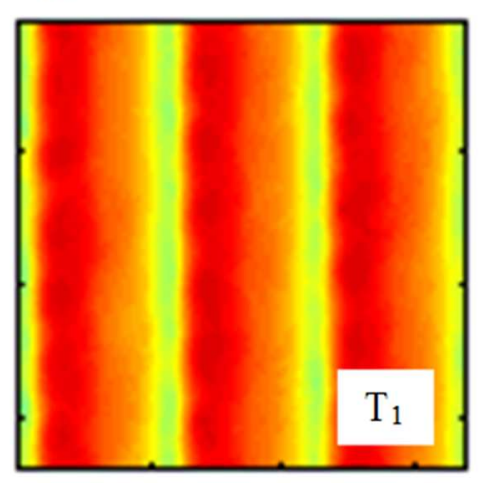

(c)

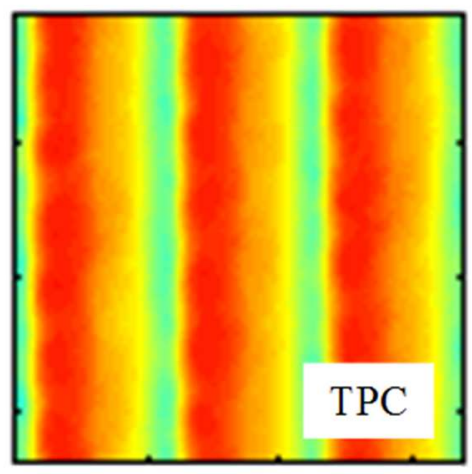

(e) (b)
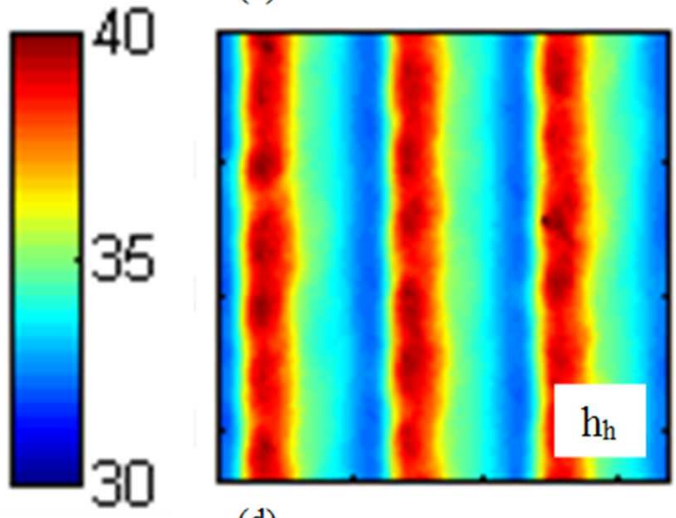

(d)

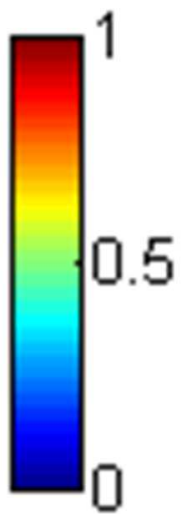

Main flow direction

Figure 9: Diamond_2 configuration: (a) Polynet Diamond spacer orientation; (b) acquired snapshot; (c) Temperature distribution colour map $\left[{ }^{\circ} \mathrm{C}\right]$; (d) Heat transfer coefficient distribution colour map $\left[\mathrm{W} \mathrm{m}^{-2} \mathrm{~K}^{-1}\right]$; (e) Temperature Polarization Coefficient colour map [-]; (f) efficiency loss coefficient colour map [-]. $\mathrm{Q}_{\mathrm{h}}=153 \mathrm{l} / \mathrm{h}(\mathrm{Re}=530) ; \mathrm{T}_{\mathrm{h} \_ \text {mean }}=40.3{ }^{\circ} \mathrm{C} ; \mathrm{T}_{\mathrm{c} \_ \text {mean }}=21.6{ }^{\circ} \mathrm{C}$.

The results relevant to the Diamond_3 configuration $\left(\xi=0^{\circ}\right.$, i.e. flow parallel to the filaments touching the active wall) are reported in Figure 10. In this case only two zones can be recognized, a low heat transfer zone where only conductive heat transfer occurs and an intermediate-high heat transfer region. This is not surprising since the fluid touching the TLC sheet moves parallel to the filament array without encountering any obstacle thus resulting in a lower mixing and in a higher $\tau$ value with respect to the other two spacer orientations. 


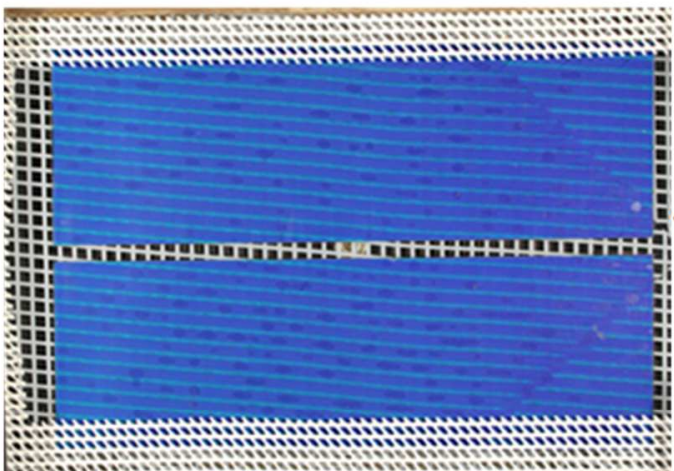

Main flow

direction

(a)

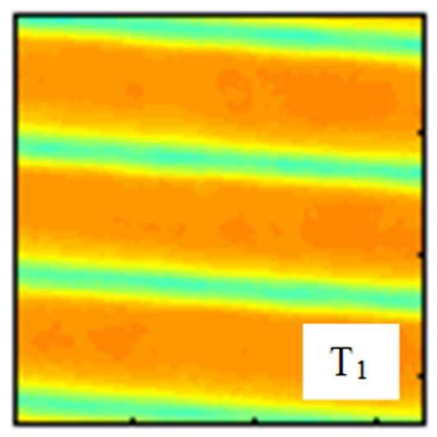

(c)

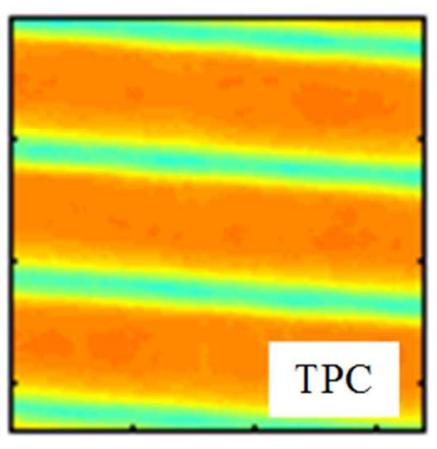

(e) (b)
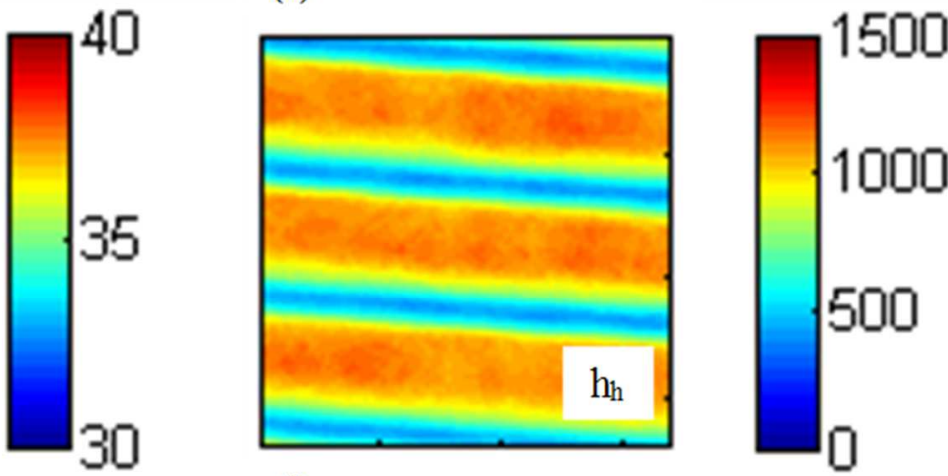

(d)
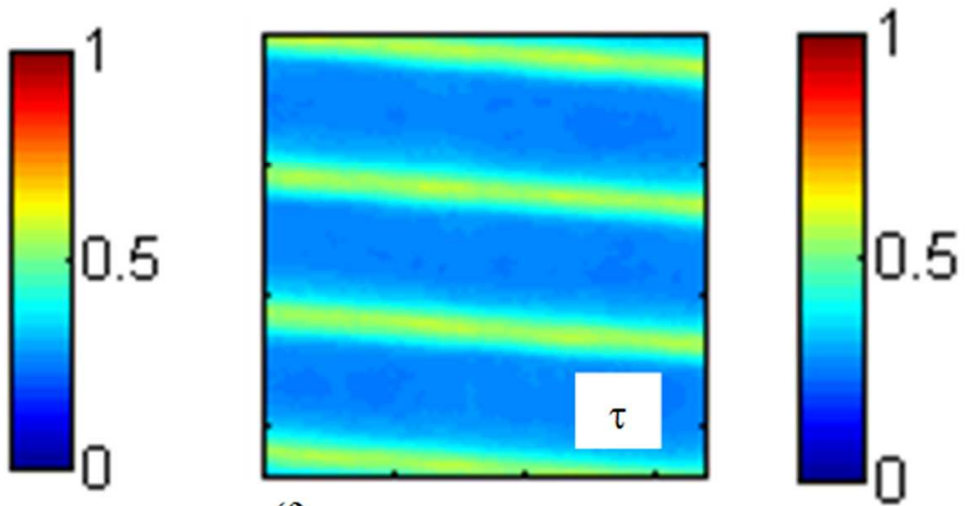

(f)

Figure 10: Diamond_3 configuration: (a) Polynet Diamond spacer orientation; (b) acquired snapshot; (c) Temperature distribution colour map $\left[{ }^{\circ} \mathrm{C}\right]$; (d) Heat transfer coefficient distribution colour map $\left[\mathrm{W} \mathrm{m}^{-2} \mathrm{~K}^{-1}\right.$ ]; (e) Temperature Polarization Coefficient colour map [-]; (f) efficiency loss coefficient colour map [-]. $\mathrm{Q}_{\mathrm{h}}=159 \mathrm{l} / \mathrm{h}(\mathrm{Re}=553) ; \mathrm{T}_{\mathrm{h} \_ \text {mean }}=39.5^{\circ} \mathrm{C} ; \mathrm{T}_{\mathrm{c} \_ \text {mean }}=21.7^{\circ} \mathrm{C}$.

\subsubsection{Delstar Diamond spacer with $\xi=\sim 45^{\circ}$}

The Delstar diamond spacer is characterized by a lower filament diameter and pitch than the Polynet. It is also more irregular (e.g. filaments are not perfectly cylindrical). In Figure 11 the results relevant to the $45^{\circ}$ orientation (Diamond_1s configuration) are reported. In this case the contact areas between TLC sheet and spacer wires are less regular and less continuous due to 
spacer's irregularity. In particular minimum $h_{h}$ values were found in the points where the two filament arrays (the upper and the lower one) intersect. As a difference from the Polynet spacer, here the filament array not in contact with the TLC surface appears to affect the temperature distribution.
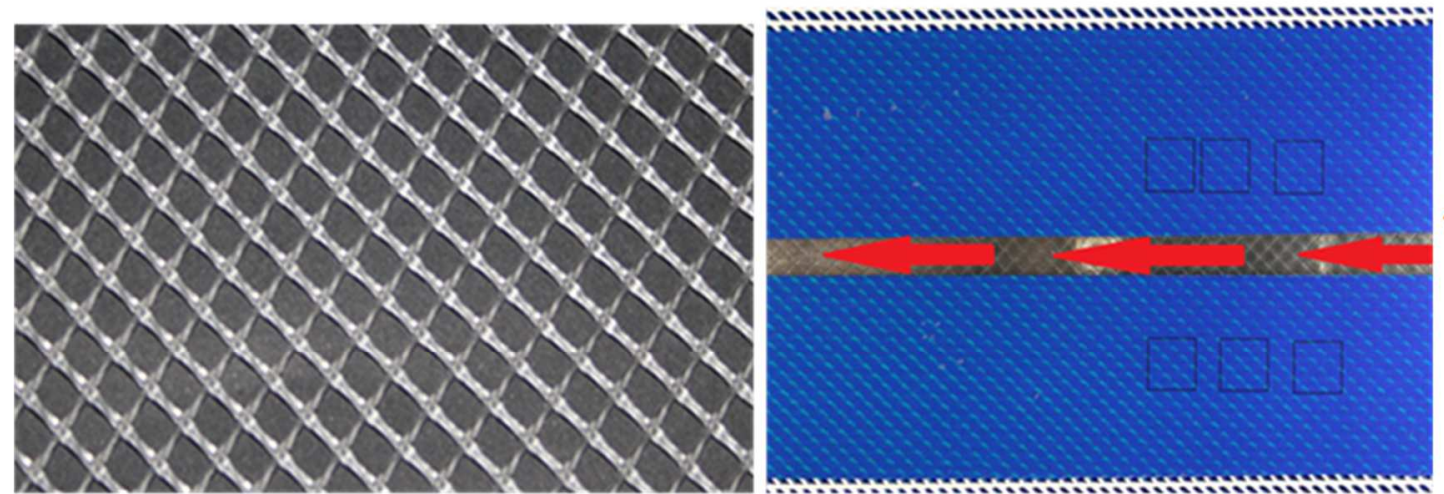

(a)

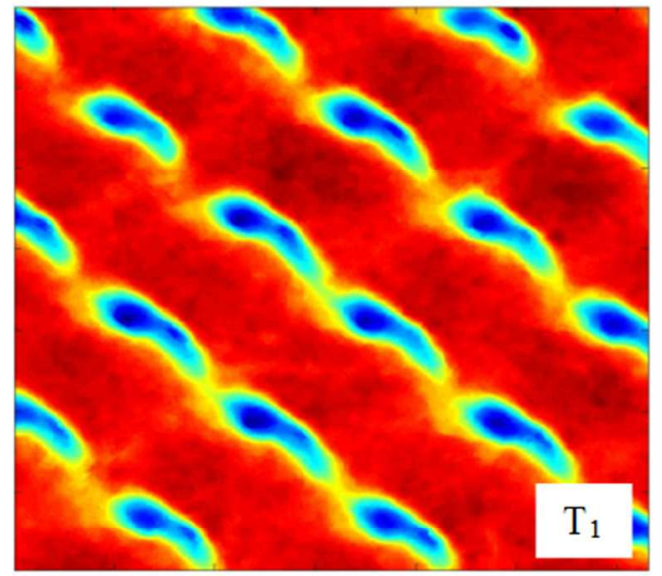

(c)

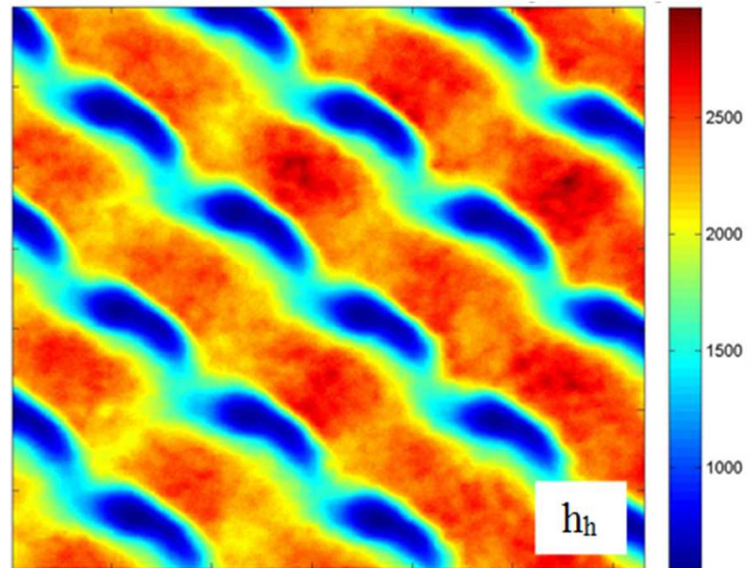

(e)
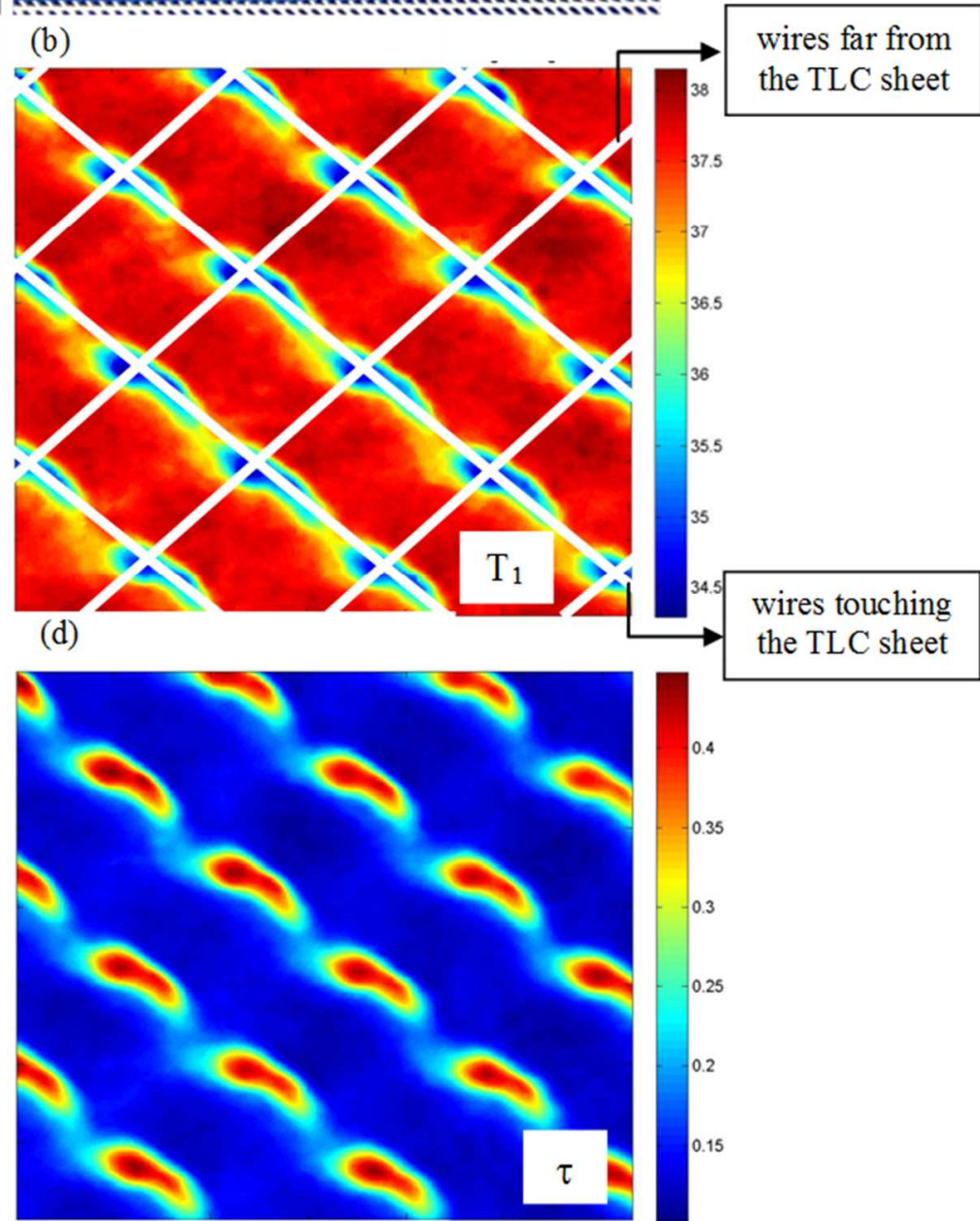

(f)

Figure 11: Diamond_1s configuration: (a) Delstar Diamond spacer orientation; (b) acquired snapshot; (c) Temperature distribution colour map $\left[{ }^{\circ} \mathrm{C}\right]$; (d) Temperature distribution colour map along with the indication of the spacer wires $\left[{ }^{\circ} \mathrm{C}\right]$; (e) Heat transfer coefficient distribution colour map $\left[\mathrm{W} \mathrm{m}^{-2} \mathrm{~K}^{-1}\right]$; (f) efficiency loss coefficient colour map [-]. $\mathrm{Q}_{\mathrm{h}}=158 \mathrm{l} / \mathrm{h}(\mathrm{Re}=552) ; \mathrm{T}_{\mathrm{h}}$ mean $=38.8^{\circ} \mathrm{C}$; $\mathrm{T}_{\mathrm{C} \_ \text {mean }}=20.1^{\circ} \mathrm{C}$. 
Intermediate heat transfer coefficients were found about in the middle of the spacer mesh, while the highest values of $h_{h}$ are located in the zones where the fluid passes between the active wall and the filament array not touching it: the restricted cross section due to the presence of the opposite filament array causes the fluid velocity to increase thus (i) enhancing the heat transfer rate and (ii) reducing the efficiency loss coefficient.

\subsubsection{Delstar Diamond spacer with $\xi=\sim 30-60^{\circ}$}

This second spacer supplied by Delstar is very similar to the previous one. The main difference concerns the different angle between the two filament arrays: as reported in Table 1 the two wire arrays form angles of $60^{\circ}$ and $120^{\circ}$. In the Diamond_30s configuration the angle between the main flow direction and the wires is $30^{\circ}$. The results relevant to this spacer-filled channel configuration are reported in Figure 12. As already discussed in the former section, the Delstar spacers are quite irregular thus resulting in a discontinuous contact between wires and TLC sheet: also in this case minimum $T_{1}$ and $h_{h}$ values were found only in the points where the wire arrays intersect (Figure $12 \mathrm{c}, \mathrm{e})$. In this case, the distribution of wall temperature and derived quantities is more complex and difficult to interpret than in the previous case, probably due to the irregularity of the geometry. At the same time, heat transfer appear to be more effective than in all the previous cases (Figure 12f).

As concerns the other orientation of this spacer named Diamond_60s configuration, a particular behaviour was found. As it can be seen in Figure 13c,f, both the $T_{1}$ and the $\tau$ colour maps show clear hexagonal regions where heat transfer is not effective. This singular temperature field is difficult to be correlated to the spacer features, it is likely to be the result of the complex 3-D flow field taking place within this specific configuration. Heat transfer appears favoured within each of these hexagonal structures thus suggesting the existence of good mixing conditions in these regions. 
The very low values of the efficiency loss coefficient (Figure 13f) highlight the very promising performance of the present configuration.

Summarizing, it can be stated that the present technique is able to capture the different thermal behaviour exhibited by each spacer-filled channel configuration highlighting how the spacer can dramatically modify the fluid flow field and the corresponding local temperature on the TLCs surface. A comparison among all the configurations investigated is reported in the following section. 


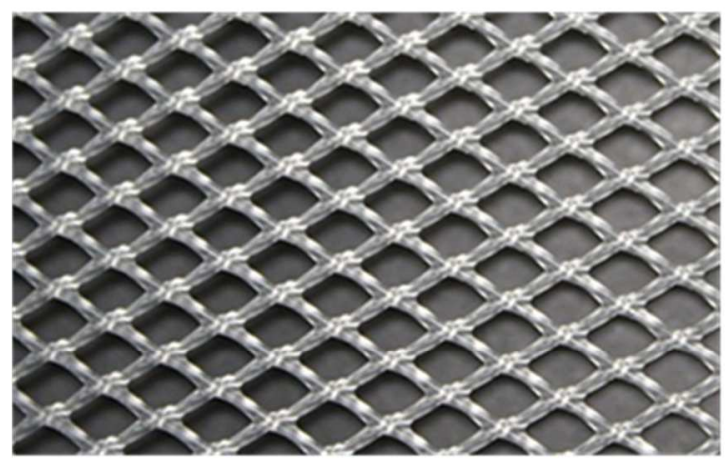

(a)

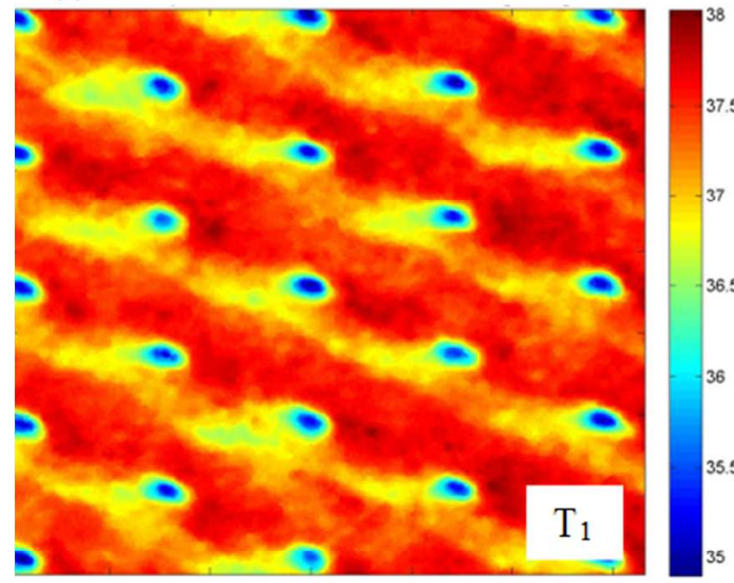

(c)

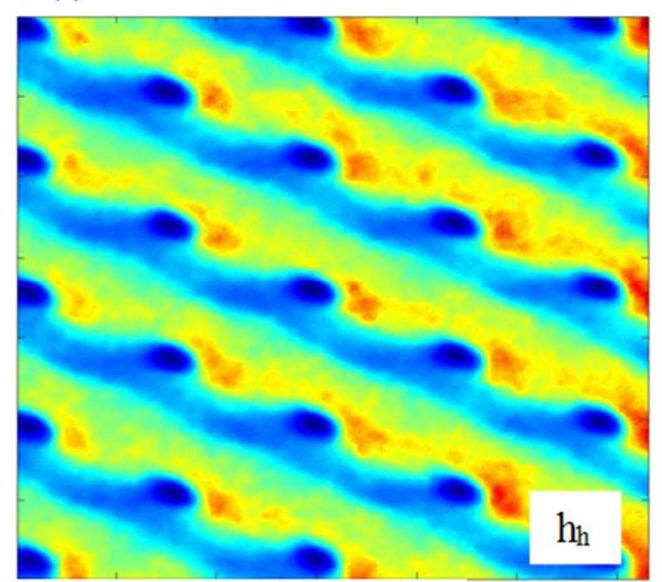

(e)

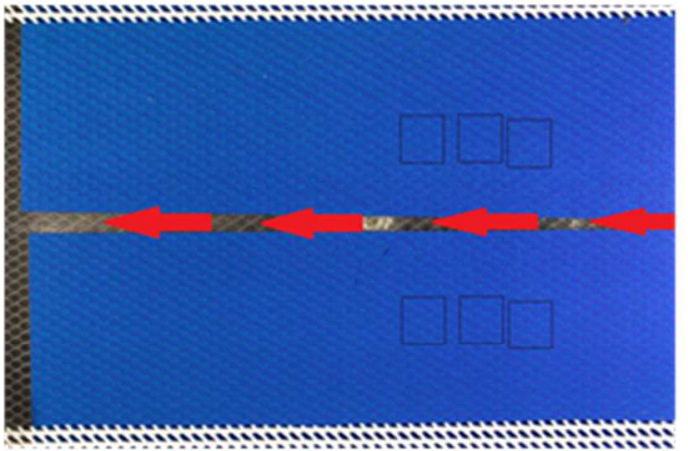

(b)

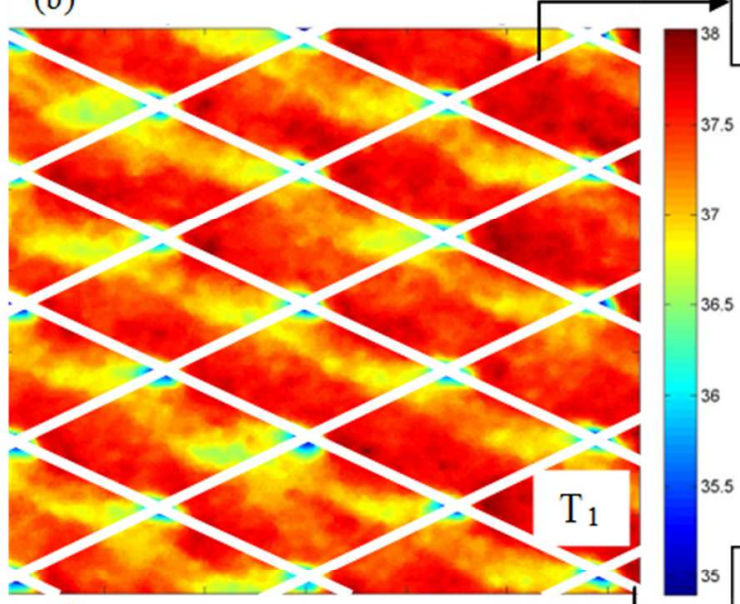

wires touching the TLC sheet

Figure 12: Diamond_30s configuration: (a) Delstar Diamond spacer orientation; (b) acquired photo; (c) Temperature distribution colour map $\left[{ }^{\circ} \mathrm{C}\right]$; (d) Temperature distribution colour map along with the indication of the spacer wires $\left[{ }^{\circ} \mathrm{C}\right]$; (e) Heat transfer coefficient distribution colour map $\left[\mathrm{W} \mathrm{m}^{-2} \mathrm{~K}^{-1}\right]$; (f) efficiency loss coefficient colour map [-]. $\mathrm{Q}_{\mathrm{h}}=122 \mathrm{1} / \mathrm{h}(\mathrm{Re}=427)$; $\mathrm{T}_{\mathrm{h} \_ \text {mean }}=38.2^{\circ} \mathrm{C}$; $\mathrm{T}_{\mathrm{c} \_ \text {mean }}=20.2^{\circ} \mathrm{C}$. 


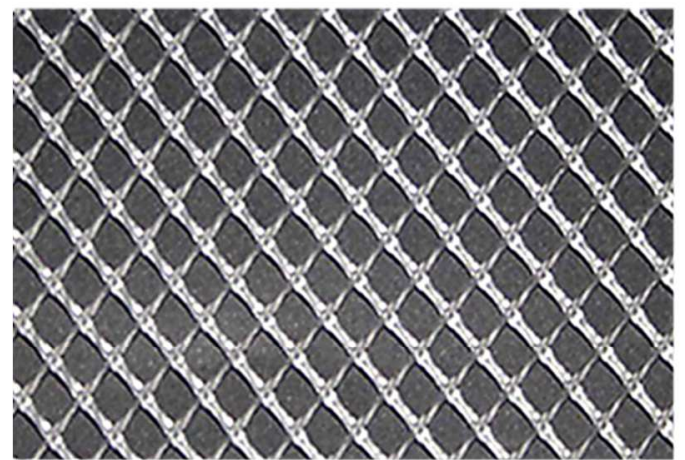

(a)

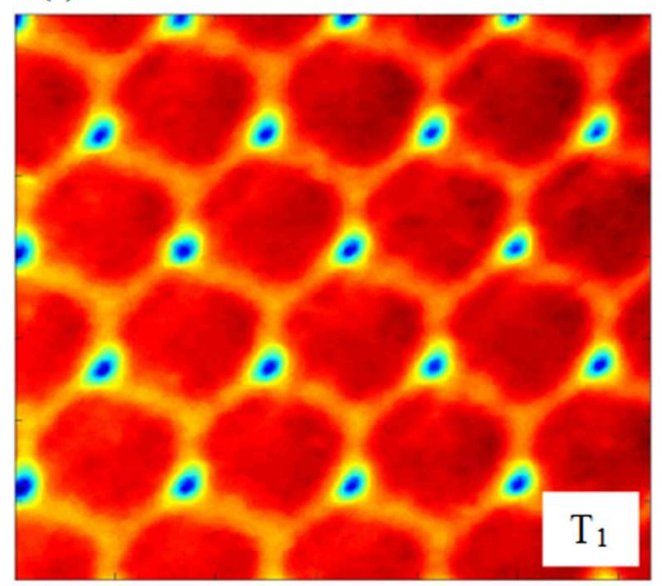

(c)

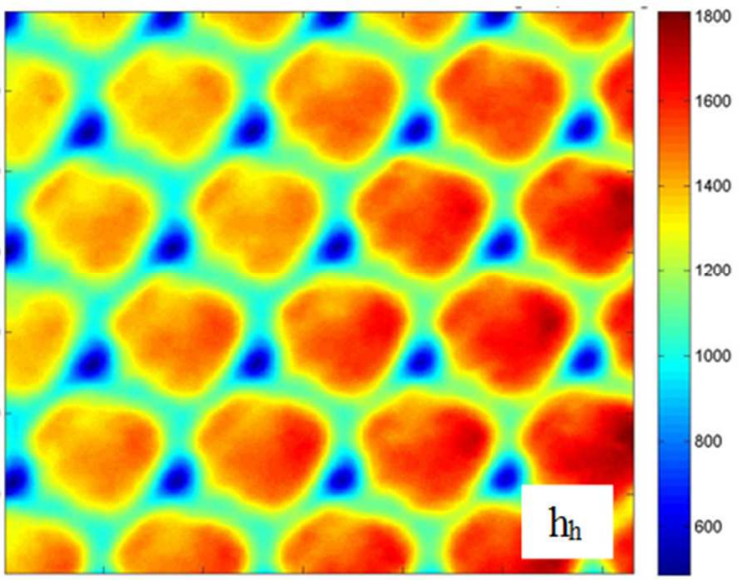

(e)

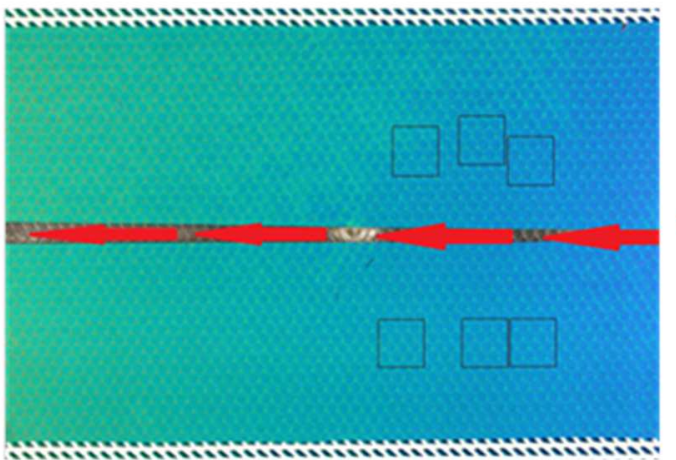

(b)
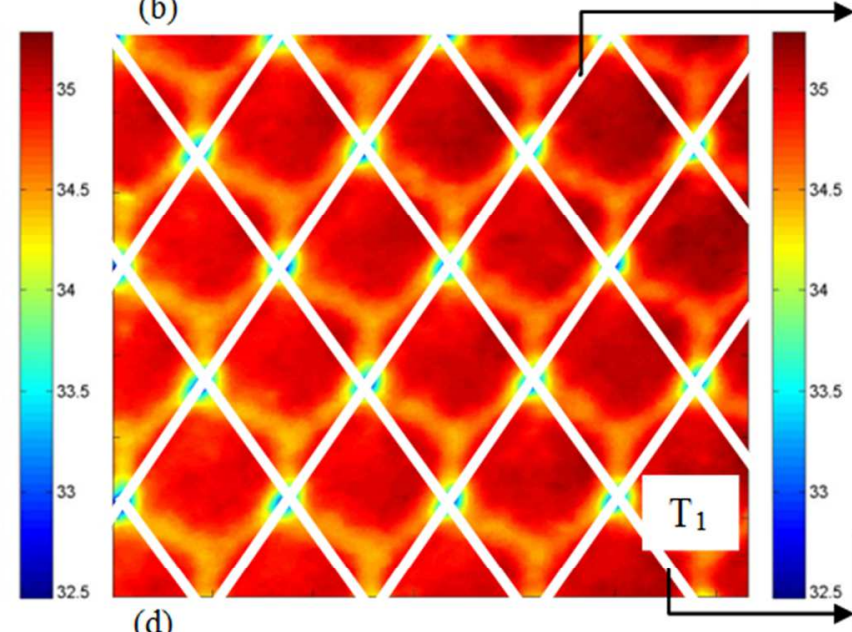

(d)

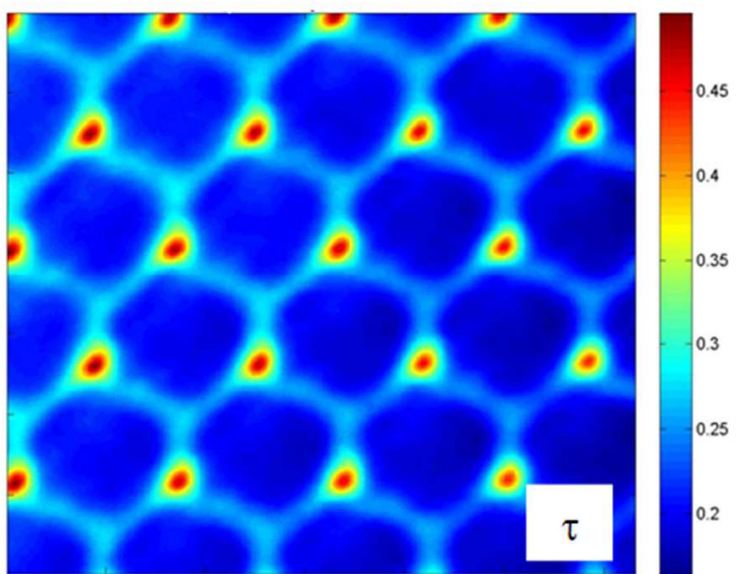

(f)

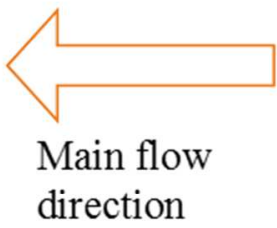

wires touching the TLC sheet

Figure 13: Diamond_60s configuration: (a) Delstar Diamond spacer configuration; (b) acquired photo; (c) Temperature distribution colour map $\left[{ }^{\circ} \mathrm{C}\right]$; (d) Temperature distribution colour map along with the indication of the spacer wires $\left[{ }^{\circ} \mathrm{C}\right]$; (e) Heat transfer coefficient distribution colour map $\left[\mathrm{W} \mathrm{m}^{-2} \mathrm{~K}^{-1}\right]$; (f) efficiency loss coefficient colour map [-]. $\mathrm{Q}_{\mathrm{h}}=38 \mathrm{l} / \mathrm{h}(\mathrm{Re}=131)$; $\mathrm{T}_{\mathrm{h} \_m e a n}=35.9^{\circ} \mathrm{C}$; $\mathrm{T}_{\mathrm{c} \text { mean }}=20.3^{\circ} \mathrm{C}$.

\subsection{Comparison among spacer-filled channels}

First of all, the fluid dynamic behaviour of the spacer-filled channels tested will be discussed, with special reference to the dependence of the Fanning friction factor on the Reynolds number. Coherently with the definition of the Reynolds number (eq. 3), the friction factor was defined as: 


$$
f=\frac{\Delta P}{l} \frac{d_{h, \text { void }}}{2 \rho u_{\text {void }}^{2}}
$$

In this way all the spacer-filled channels can be compared to the corresponding empty channels of the same height and mass flow rate, thus highlighting how each spacer modifies fluid flow and transport features ([16]).

Results are reported in Figure 14. All the configurations tested but the Diamond_60s exhibit similar f vs Re trends. The different behaviour of the Diamond_60s indicates that this configuration is by far the most effective in promoting flow separation and energy dissipation.

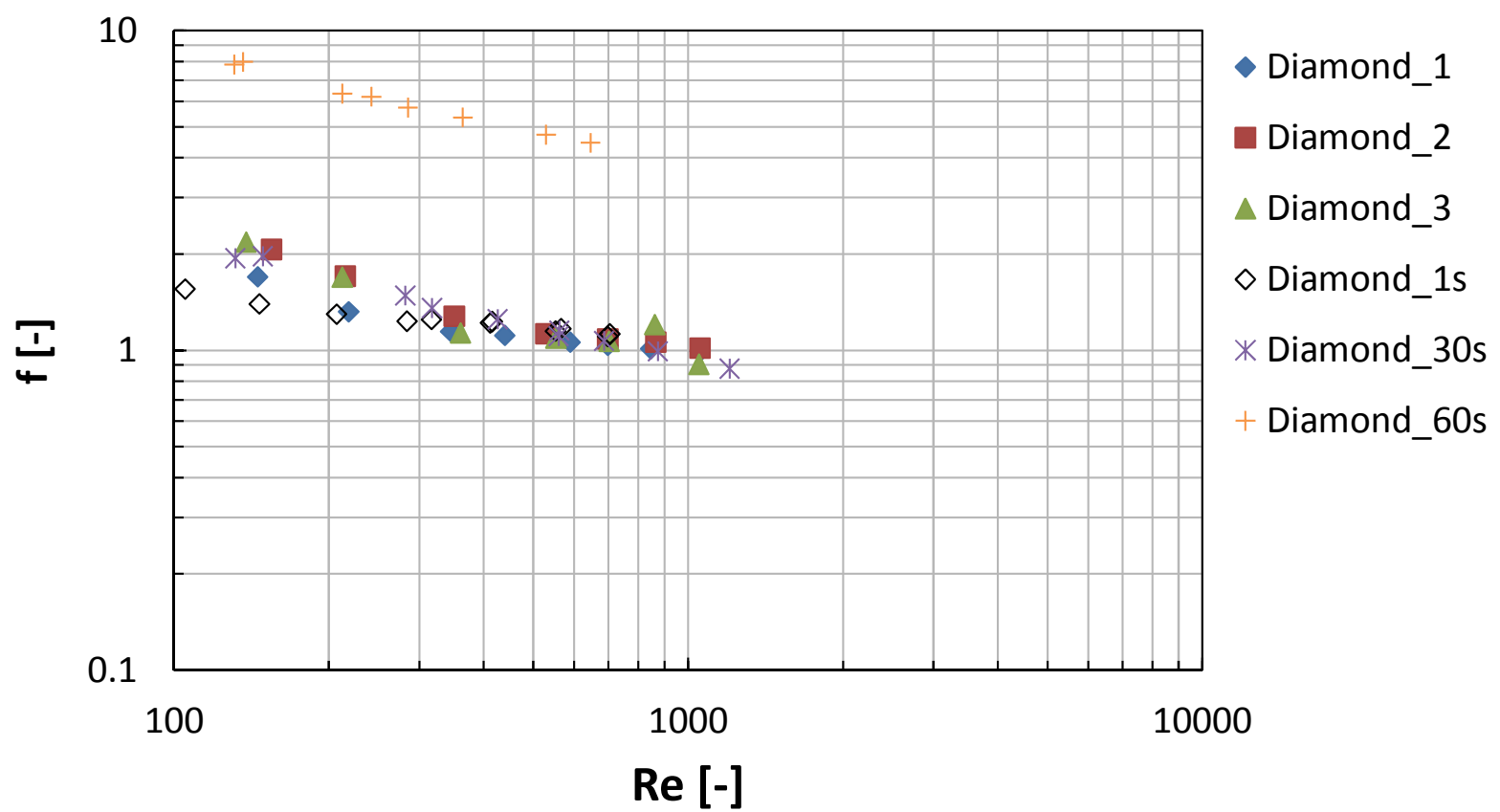

Figure 14: Fanning friction factor as a function of the Reynolds number.

In Figure 15 the comparison among the spacer configuration concerns the Nusselt number and the average efficiency loss coefficient. $\mathrm{Nu}$ is defined as:

$N u=\frac{h_{h, \text { mean }} d_{h, \text { void }}}{k}$ 
where $h_{h \text {,mean }}$ is the mean heat transfer coefficient provided by the present technique. The comparison includes also the Nusselt number in an equivalent channel empty of spacer, for which a value of 5.38 was calculated by analytically solving the Navier-Stokes and energy equations for parallel flow in a flat rectangular channel confined by an adiabatic wall on one side and a uniform heat flux wall on the other. By observing Figure 15a, it can be seen that in most cases the dependence of $\mathrm{Nu}$ on $\mathrm{Re}$ is strongest at the lowest Re, while it decreases at larger Re: as reported by other authors $([48,63])$, the mixing enhancement due to the presence of the spacer is larger at low flow rates, while it decreases at larger flow rates where the fluid is better mixed also because of increased inertial effects. The data relevant to each spacer were fitted by a power law as $\mathrm{Nu}=\mathrm{a} \mathrm{Re}^{\mathrm{b}}$. All the exponents $\mathrm{b}$ were found to be between $\sim 0.5$ and $\sim 0.6$. Similar exponents $(0.55-0.61)$ were found by Chernyshov et al. [49] for the case of air gap membrane distillation.

Interestingly, for the case of the Diamond_3 configuration at the lowest flow rate, a Nu value lower than the one relevant to the empty channel was found thus indicating a detrimental effect of the spacer. As it can be seen the Diamond_60s provides the highest $\mathrm{Nu}$ at a given Re coherently with the fact that the corresponding pressure drop is also the highest. As concerns the Polynet spacer, the Diamond_1 configuration $\left(\xi=45^{\circ}\right)$ appears to be the most efficient, while the Diamond_3 configuration $\left(\xi=0^{\circ}\right)$ exhibits the worst performance. Identical considerations can be inferred by observing the corresponding data relevant to $\tau$ in Figure 15b: the hierarchy of spacer configurations performance observable in Figure 15a is basically reversed also in Figure 15b (only the Diamond_1/Diamond_1s configuration hierarchy exhibits an inversion due to the difference in channel height). For instance, also in this graph, the Diamond_3 configuration provides the worst results because of a poor convective heat transfer perpendicularly to the TLC sheet. Clearly, as expected, polarization effects decrease as the flow rate increases. All these results are in accordance with those by Shakaib et al. [33] and Gurreri et al. [64] on diamond spacers: a better spacer performance from the point of view of heat transfer is obtained when (i) the fluid flow direction 
bisects the angle between the filaments, and (ii) the filaments are arranged at about $60^{\circ}$ with respect to the flow.

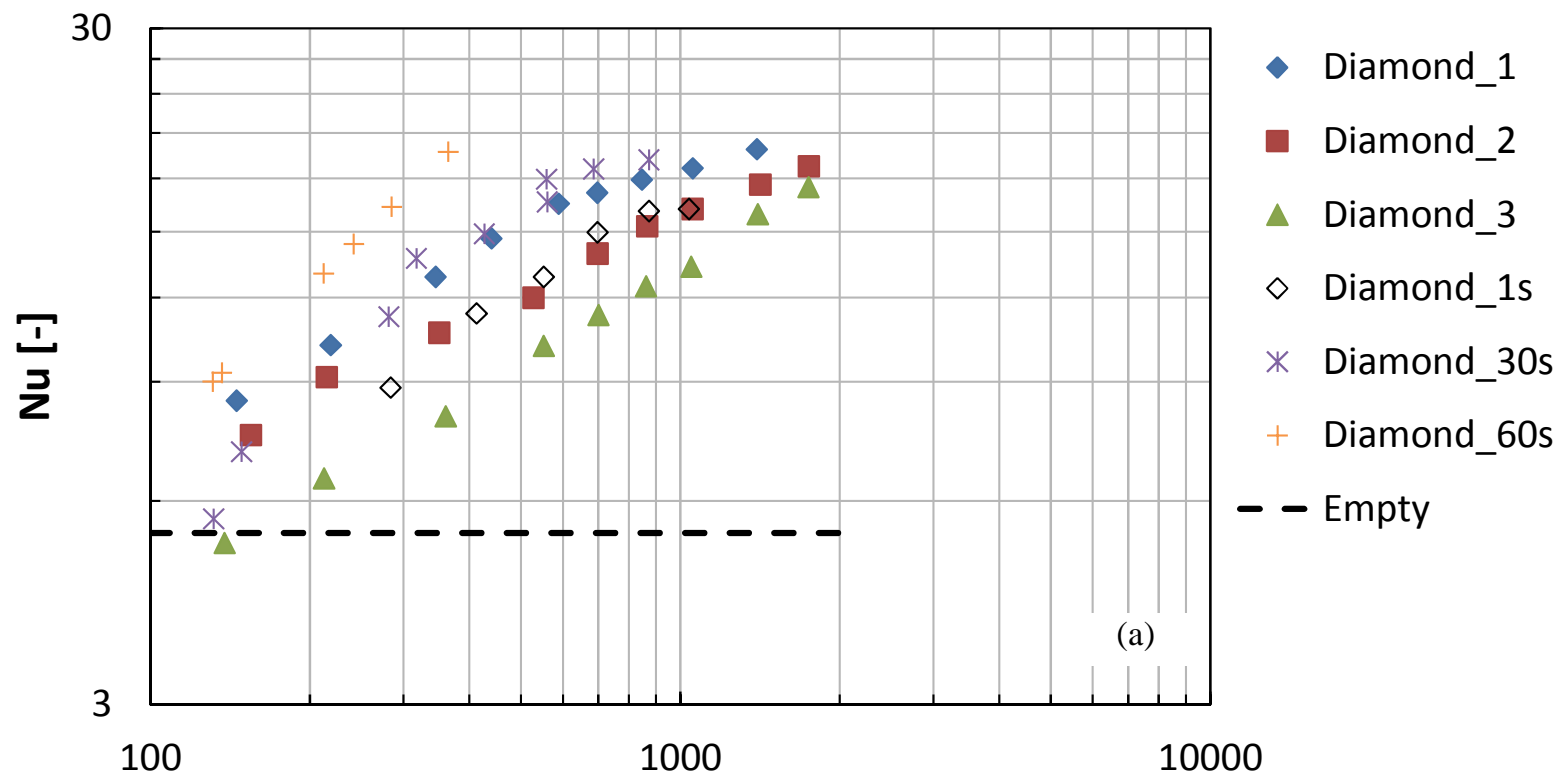

$\operatorname{Re}[-]$

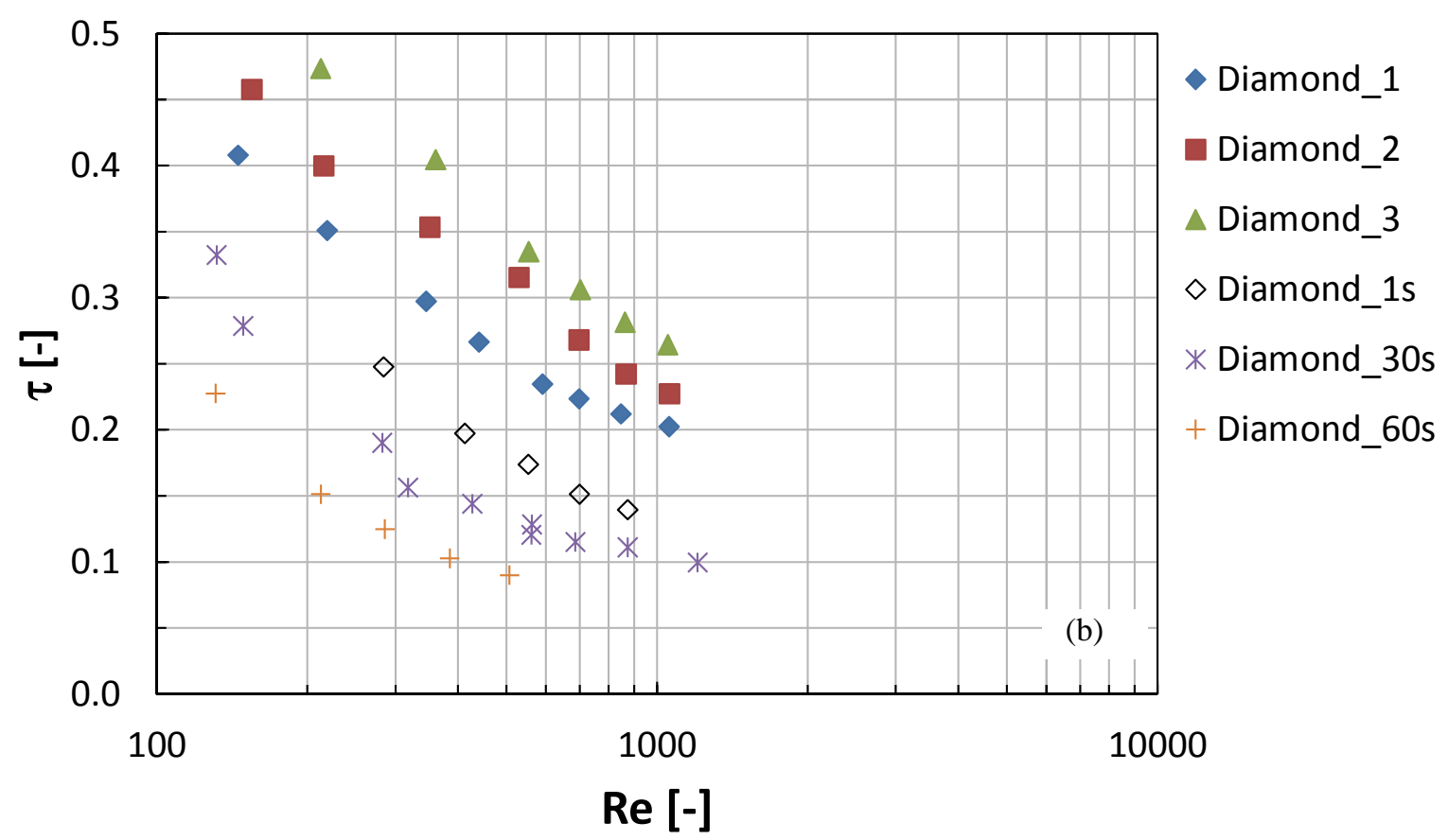

Figure 15: Nusselt number (a) and efficiency loss coefficient (b) as a function of the Reynolds number.

It is worth noting that the comparison between the spacer configuration performances reported in Figure 15 and just discussed concerns only the heat transfer features as functions of the flow rate. 
Clearly, pumping power should be also taken into account in order to establish which is the most promising configuration. Therefore, as suggested by the literature $([22,26,34])$ a dimensionless power number $P n$ was used. It is defined as:

$$
P n=\operatorname{SPC} \frac{\rho^{2} h_{s p}^{4}}{\mu^{3}}=\frac{\Delta P}{l} u_{v o i d} \frac{\rho^{2} h_{s p}^{4}}{\mu^{3}}=\frac{1}{8} f \mathrm{Re}^{3}
$$

where SPC is the specific power consumption.

The Nusselt number and the efficiency loss coefficient $\tau$ are reported as functions of the power number Pn for the spacers investigated in Figure 16. Clearly, low $\tau$ with low Pn is the preferable condition. As it can be seen in Figure 16a, at a given Pn number, the employment of a net spacer within the channel guarantees $\mathrm{Nu}$ numbers higher than those relevant to the empty spacer thus confirming the soundness of this choice. However, it is worth observing that such convenience gradually decreases as Pn decreases (i.e. low Re, high f): in these conditions, as also shown by Figure 15a, employing a net spacer may be economically disadvantageous with respect to a spacerless channel. Since a spacer is however necessary to support the membrane, for low flow rates applications it could be more economically efficient using a spacer constituted by filaments parallel to the main flow direction only.

The $\tau$ vs Pn trends reported in Figure 16b confirm that the Diamond_3 configuration is the worst one, probably because of the low velocity components perpendicular to the TLC sheet. The configurations where the main fluid direction does not bisect the spacer wires are confirmed to be less convenient. Notably, since the dependence of $\mathrm{f}$ on $\mathrm{Re}$ is very similar for the various configurations (Figure 14), analogous considerations can be inferred from Figure 15b and Figure 16b. The only exception is represented by the Diamond_60s configuration which exhibited f values larger than those relevant to the other configurations. 

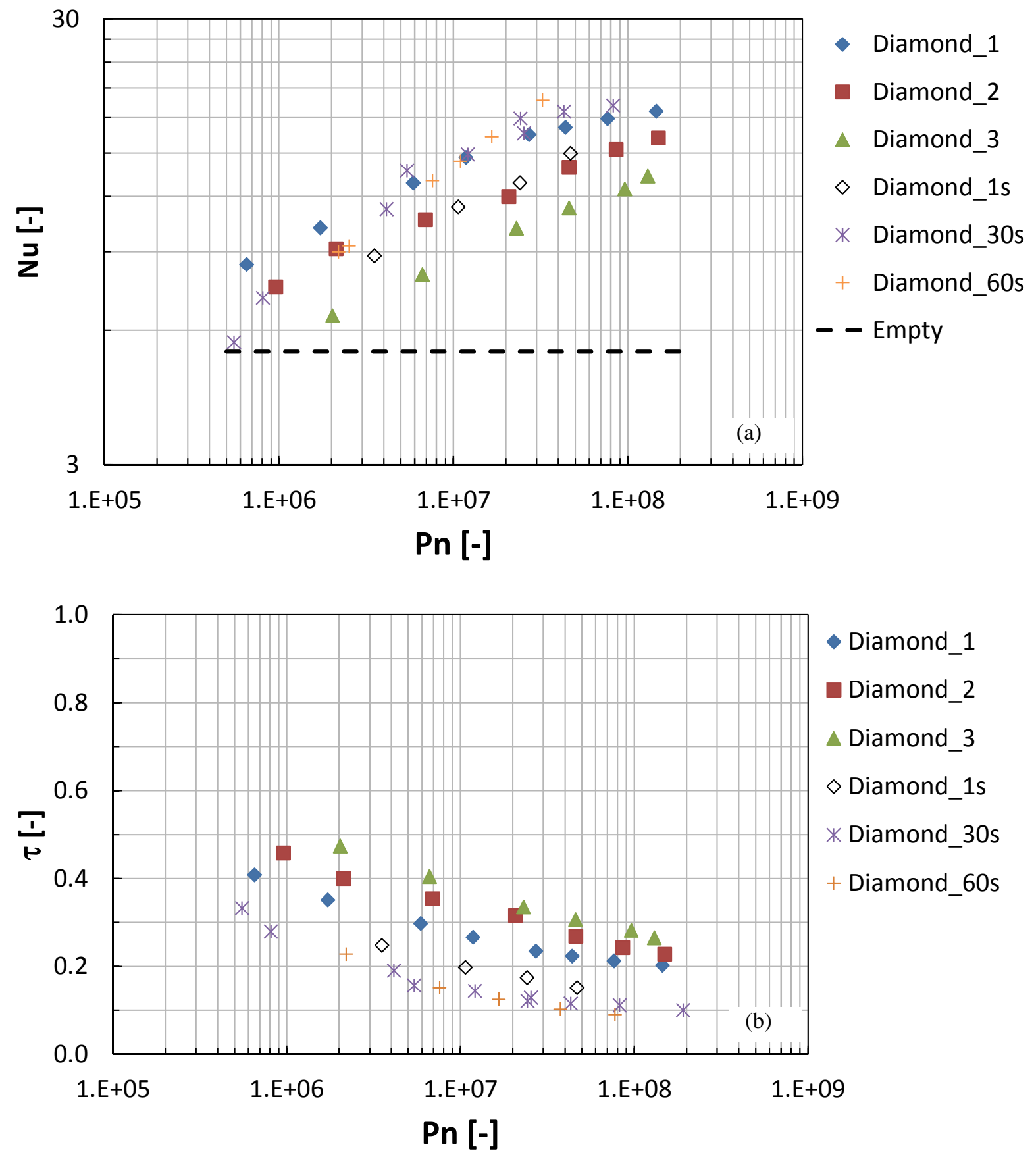

Figure 16: Nusselt number (a) and efficiency loss coefficient (b) as a function of the Power number.

As shown in Figure $16 \mathrm{~b}$ the $\tau$ values exhibited by the Diamond_60s configuration at a given Pn value are very similar to those of Diamond_30s: therefore, the better heat transfer enhancement provided by the Diamond_60s (with respect to the Diamond_30s) configuration is almost exactly counterbalanced by the higher pressure drops it generates. Moreover, interestingly the different 
mesh size of Diamond_1s (with respect to Diamond_30s and Diamond_60s) provides larger temperature polarization effects.

Finally, it is worth noting that the geometrical features of Delstar spacers inclusive of irregularities guarantee, at a given pumping power, reductions of the polarization phenomena larger than those provided by the Polynet ones.

\section{CONCLUSIONS}

A novel space-resolved experimental technique recently proposed by the same authors ([58]) and based on the employment of Thermochromic Liquid Crystals has been here adopted to study the heat transfer performance of some commercial spacers. In particular different orientations of some Diamond spacers with different geometrical features were investigated. Experimental set-up along with operating conditions was chosen in order to be considered as representative of a Direct Contact Membrane Distillation module. Both local and averaged global data were provided. Notably, the possibility of performing measurements of local temperature on the interface between the hot and cold channel represents a peculiarity of the present technique. The local information collected has been then used in order to obtain distributions of heat transfer coefficient and temperature polarization on the same interface. Such local data can be considered as spacer-specific and only a few general considerations can be inferred from them:

- the contact area between the spacer wires and the TLCs sheet provides the lowest heat transfer coefficient as the heat transfer is purely conductive;

- such area is much smaller for the case of the Delstar spacers whose wires are much more irregular (leaving room for liquid passage);

- when the spacer wires touching the TLCs sheet are more regular (Polynet spacer case) and not parallel to the main flow direction, (i) regions of intermediate heat transfer coefficient can be recognized downstream these wires (due to fluid vein detachment), while (ii) high 
heat transfer coefficients and low polarizations can be found immediately upstream the wires (due to fluid vein reattachment and to the hit of the fluid with the wire).

It is also worth noting that all the local data collected could be employed as benchmark for the validation of CFD simulations.

All the local data were averaged in order to obtain global information and compare spacers' performance on the basis of global dimensionless numbers. All the spacer-filled channel configurations were found to provide similar dependence of the Fanning friction factor on the Reynolds number: only the Diamond_60s provides higher pressure drops probably because of a higher flow separation. As concerns the heat transfer features, results suggest that better spacer performance can be obtained when (i) the fluid flow direction bisects the angle between the filaments, and (ii) the filaments are arranged at about $60^{\circ}$ with respect to the flow. These findings are in agreement with others reported in the literature ([33]) thus suggesting a good reliability of the present technique. Finally, the results relevant to fluid dynamics and heat transfer were combined in order to find the most economically advantageous (among those investigated in the present work) spacer configuration. In this regard the geometrical features of the Delstar spacers inclusive of irregularities were found to provide reductions of the polarization phenomena larger than those provided by the Polynet ones at given pumping costs.

\section{ACKNOWLEDGEMENTS}

This work was carried out with the financial support of the MEDIRAS project within theEU-FP7 research programme (Contract no.TREN/FP7EN/218938). NSW (poly-nets) and Delstar Naltex are gratefully acknowledged for providing the spacer material for the tests. Dr. Marina Renda and Dr. Cristoforo Costanza are acknowledged for carrying out some of the experiments presented in this work. 


\section{NOTATION}

\begin{tabular}{|c|c|}
\hline $\mathrm{d}_{\mathrm{f}}$ & Spacer filament diameter $[\mathrm{m}]$ \\
\hline$d_{h}$ & Hydraulic diameter [m] \\
\hline f & Fanning friction factor $[-]$ \\
\hline h & Heat transfer coefficient $\left[\mathrm{W} \mathrm{m} \mathrm{m}^{-2} \mathrm{~K}^{-1}\right]$ \\
\hline $\mathrm{h}_{\mathrm{sp}}$ & Spacer thickness $[\mathrm{m}]$ \\
\hline $\mathrm{k}$ & Thermal conductivity $\left[\mathrm{W} \mathrm{m} \mathrm{m}^{-1} \mathrm{~K}^{-1}\right]$ \\
\hline 1 & Distance between the first and the last pressure taps [m] \\
\hline $1 \mathrm{~m}$ & Spacer mesh length $[\mathrm{m}]$ \\
\hline $\mathrm{P}$ & Pressure $[\mathrm{Pa}]$ \\
\hline$\Delta \mathrm{P} / 1$ & Pressure drops for unit length [bar $\left.\mathrm{m}^{-1}\right]$ \\
\hline $\mathrm{Nu}$ & Nusselt number [-] \\
\hline Pn & Power number [-] \\
\hline Q & Flow rate $\left[\mathrm{m}^{3} \mathrm{~s}^{-1}\right.$ or $\left.1 \mathrm{~h}^{-1}\right]$ \\
\hline $\operatorname{Re}$ & Reynolds number [-] \\
\hline SPC & Specific Power Consumption $\left[\mathrm{N} \mathrm{m}^{-2} \mathrm{~s}^{-1}\right]$ \\
\hline $\mathrm{T}$ & Temperature $\left[{ }^{\circ} \mathrm{C}\right]$ \\
\hline TPC & Temperature Polarization Coefficient [-] \\
\hline & Velocity $\left[\mathrm{m} \mathrm{s}^{-1}\right]$ \\
\hline
\end{tabular}

\section{Greek letters}

$\varepsilon$

$\mu \quad$ Viscosity [Pa s]

$\rho \quad$ Density $\left[\mathrm{kg} \mathrm{m}^{-3}\right]$

$\theta \quad$ Angle between crossing filaments $\left[{ }^{\circ}\right]$

$\tau \quad$ Efficiency loss coefficient [-]

$\xi$
Spacer porosity [-]

Angle between main flow direction and the filament array touching the TLS sheet $\left[^{\circ}\right]$

\section{Subscripts}
c
Cold channel
$\mathrm{h}$
Hot channel
TLC
Thermochromic Liquid Crystal 


\section{REFERENCES}

[1] A. AlHathal Al-Anezi, A.O. Sharif, M.I. Sanduk, A.R. Khan, Potential of membrane distillation - A comprehensive review, International Journal of Water, 7 (2013) 317-346.

[2] A. Cipollina, M.G. Di Sparti, A. Tamburini, G. Micale, Development of a Membrane Distillation module for solar energy seawater desalination, Chem. Eng. Res. Des., 90 (2012) 21012121.

[3] Y.-D. Kim, K. Thu, N. Ghaffour, K. Choon Ng, Performance investigation of a solar-assisted direct contact membrane distillation system, J. Membr. Sci., 427 (2013) 345-364.

[4] J. Koschikowski, M. Wieghaus, M. Rommel, Solar thermal-driven desalination plants based on membrane distillation, Desalination, 156 (2003) 295-304.

[5] J. Koschikowski, M. Wieghaus, M. Rommel, V.S. Ortin, B.P. Suarez, J.R. Betancort Rodríguez, Experimental investigations on solar driven stand-alone membrane distillation systems for remote areas, Desalination, 248 (2009) 125-131.

[6] N. Palanisami, K. He, I.S. Moon, Utilization of solar energy for direct contact membrane distillation process: An experimental study for desalination of real seawater, Korean J. Chem. Eng., 31 (2014) 155-161.

[7] R. Porrazzo, A. Cipollina, M. Galluzzo, G. Micale, A neural network-based optimizing control system for a seawater-desalination solar-powered membrane distillation unit, Computers \& Chemical Engineering, 54 (2013) 79-96.

[8] M.R. Qtaishat, F. Banat, Desalination by solar powered membrane distillation systems, Desalination, 308 (2013) 186-197.

[9] R. Schwantes, A. Cipollina, F. Gross, J. Koschikowski, D. Pfeifle, M. Rolletschek, V. Subiela, Membrane distillation: solar and waste heat driven demonstration plants for desalination, Desalination, 323 (2013) 93-106.

[10] M. Shatat, S.B. Riffat, Water desalination technologies utilizing conventional and renewable energy sources, International Journal of Low-Carbon Technologies, 9 (2014) 1-19.

[11] M.S. El-Bourawi, Z. Ding, R. Ma, M. Khayet, A framework for better understanding membrane distillation separation process, J. Membr. Sci., 285 (2006) 4-29.

[12] Y.M. Manawi, M. Khraisheh, A.K. Fard, F. Benyahia, S. Adham, Effect of operational parameters on distillate flux in direct contact membrane distillation (DCMD): Comparison between experimental and model predicted performance, Desalination, 336 (2014) 110-120.

[13] K.W. Lawson, D.R. Lloyd, Membrane distillation, J. Membr. Sci., 124 (1997) 1-25.

[14] R.W. Schofield, A.G. Fane, C.J.D. Fell, Heat and mass transfer in membrane distillation, J. Membr. Sci., 33 (1987) 299-313.

[15] A.R. Da Costa, A.G. Fane, D.E. Wiley, Spacer characterization and pressure drop modelling in spacer filled channel for ultrafiltration, Journal of Membrane Science, 87 (1994) 79-98.

[16] G. Schock, A. Miquel, Mass transfer and pressure loss in spiral wound modules, Desalination, 64 (1987) 339-352.

[17] L. Gurreri, A. Tamburini, A. Cipollina, G. Micale, CFD analysis of the fluid flow behavior in a reverse electrodialysis stack, Desalin. Water Treat., 48 (2012) 390-403.

[18] L. Gurreri, A. Tamburini, A. Cipollina, G. Micale, M. Ciofalo, CFD simulation of mass transfer phenomena in spacer filled channels for reverse electrodialysis applications, Chem. Eng. Trans., 32 (2013) 1879-1884. 
[19] S.K. Karode, A. Kumar, Flow visualization through spacer filled channels by computational fluid dynamics I. Pressure drop and shear rate calculations for flat sheet geometry, J. Membr. Sci., 193 (2001) 69-84.

[20] C.P. Koutsou, S.G. Yiantsios, A.J. Karabelas, Direct numerical simulation of flow in spacerfilled channels: Effect of spacer geometrical characteristics, J. Membr. Sci., 291 (2007) 53-69.

[21] C.P. Koutsou, S.G. Yiantsios, A.J. Karabelas, A numerical and experimental study of mass transfer in spacer-filled channels: Effects of spacer geometrical characteristics and Schmidt number, J. Membr. Sci., 326 (2009) 234-251.

[22] F. Li, W. Meindersma, A.B. de Haan, T. Reith, Optimization of commercial net spacers in spiral wound membrane modules, J. Membr. Sci., 208 (2002) 289-302.

[23] F. Li, W. Meindersma, A.B. de Haan, T. Reith, Experimental validation of CFD mass transfer simulations in flat channels with non-woven net spacers, J. Membr. Sci., 232 (2004) 19-30.

[24] F. Li, W. Meindersma, A.B. de Haan, T. Reith, Novel spacers for mass transfer enhancement in membrane separations, J. Membr. Sci., 253 (2005) 1-12.

[25] Y.L. Li, K.L. Tung, CFD simulation of fluid flow through spacer-filled membrane module: selecting suitable cell types for periodic boundary conditions, Desalination, 233 (2008) 351-358.

[26] J. Liu, A. Iranshahi, Y. Lou, G. Lipscomb, Static mixing spacers for spiral wound modules, J. Membr. Sci., 442 (2013) 140-148.

[27] V.V. Ranade, A. Kumar, Fluid dynamics of spacer filled rectangular and curvilinear channels, J. Membr. Sci., 271 (2006) 1-15.

[28] L.C. Santos, V. Geraldes, S. Velizarov, J.G. Crespo, Investigation of flow patterns and mass transfer in membrane module channels filled with flow-aligned spacers using computational fluid dynamics (CFD), J. Membr. Sci., 305 (2007) 103-117.

[29] J. Schwinge, D.E. Wiley, A.G. Fane, Novel spacer design improves observed flux, J. Membr. Sci., 229 (2004) 53-61.

[30] J. Schwinge, D.E. Wiley, D.F. Fletcher, Simulation of the Flow around Spacer Filaments between Channel Walls. 1. Hydrodynamics, Ind. Eng. Chem. Res., 41 (2002) 2977-2987.

[31] J. Schwinge, D.E. Wiley, D.F. Fletcher, Simulation of the Flow around Spacer Filaments between Channel Walls. 2. Mass-Transfer Enhancement, Ind. Eng. Chem. Res., 41 (2002) 48794888.

[32] J. Schwinge, D.E. Wiley, D.F. Fletcher, A CFD study of unsteady flow in narrow spacer-filled channels for spiral-wound membrane modules, Desalination, 146 (2002) 195-201.

[33] M. Shakaib, S.M.F. Hasani, M. Mahmood, CFD modeling for flow and mass transfer in spacer-obstructed membrane feed channels, J. Membr. Sci., 326 (2009) 270-284.

[34] M. Shakaib, S.M.F. Hasani, M. Mahmood, Study on the effects of spacer geometry in membrane feed channels using three-dimensional computational flow modeling, J. Membr. Sci., 297 (2007) 74-89.

[35] A. Shrivastava, S. Kumar, E.L. Cussler, Predicting the effect of membrane spacers on mass transfer, J. Membr. Sci., 323 (2008) 247-256.

[36] A. Tamburini, G. La Barbera, A. Cipollina, M. Ciofalo, G. Micale, CFD simulation of channels for direct and reverse electrodialysis, Desalin. Water Treat., 48 (2012) 370-389.

[37] S. Wardeh, H.P. Morvan, CFD simulations of flow and concentration polarization in spacerfilled channels for application to water desalination, Chem. Eng. Res. Des., 86 (2008) 1107-1116.

[38] D.E. Wiley, D.F. Fletcher, Computational fluid dynamics modelling of flow and permeation for pressure-driven membrane processes, Desalination, 145 (2002) 183-186.

[39] D.E. Wiley, D.F. Fletcher, Techniques for computational fluid dynamics modeling of flow in membrane channels, J. Membr. Sci., 211 (2003) 127-137.

[40] P. Xie, L.C. Murdoch, D.A. Ladner, Hydrodynamics of sinusoidal spacers for improved reverse osmosis performance, J. Membr. Sci., 453 (2014) 92-99.

[41] A. Velázquez, J.I. Mengual, Temperature Polarization Coefficients in Membrane Distillation, Ind. Eng. Chem. Res., 34 (1995) 585-590. 
[42] L. Martínez-Diez, R.-M. J.M., Temperature and concentration polarization in membrane distillation of aqueous salt solutions, J. Membr. Sci., 156 (1999) 265-273.

[43] F. Laganà, B. G., E. Drioli, Direct contact membrane distillation: modelling and concentration experiments, J. Membr. Sci., 166 (2000) 1-11.

[44] L. Martínez-Diez, M.I. Vazquez-González, F.J. Florido-Díaz, Study of membrane distillation using channel spacers, J. Membr. Sci., 144 (1998) 45-56.

[45] Y. Yun, J. Wang, R. Ma, A.G. Fane, Effects of channel spacers on direct contact membrane distillation, Desalination and Water Treatment, 34 (2011) 63-69.

[46] J. Phattaranawik, R. Jiraratananon, A.G. Fane, C. Halim, Mass flux enhancement using filled channels in direct contact membrane distillation, J. Membr. Sci., (2001) 193-201.

[47] J. Phattaranawik, R. Jiraratananon, A.G. Fane, Heat transport and membrane distillation coefficients in direct contact membrane distillation, J. Membr. Sci., 212 (2003) 177-193.

[48] J. Phattaranawik, R. Jiraratananon, A.G. Fane, Effects of net-type spacers on heat and mass transfer in direct contact membrane distillation and comparison with ultrafiltration studies, J. Membr. Sci., 217 (2003) 193-206.

[49] M.N. Chernyshov, G.W. Meindersma, A.B. de Haan, Comparison of spacers for temperature polarization reduction in air gap membrane distillation, Desalination, 183 (2005) 363-374.

[50] L. Martínez-Diez, R.-M. J.M., Characterization of membrane distillation modules and analysis of mass flux enhancement by channel spacers, J. Membr. Sci., 274 (2006) 123-137.

[51] S. Al-Sharif, M. Albeirutty, A. Cipollina, G. Micale, Modelling flow and heat transfer in spacer-filled membrane distillation channels using open source CFD code, Desalination, 311 (2013) 103-112.

[52] A. Cipollina, A. Di Miceli, J. Koschikowski, G. Micale, L. Rizzuti, CFD simulation of a membrane distillation module channel, Desalination and Water Treatment, 6 (2009) 177-183.

[53] A. Cipollina, G. Micale, L. Rizzuti, Membrane distillation heat transfer enhancement by CFD analysis of internal module geometry, Desalination and Water Treatment, 25 (2011) 195-209.

[54] M. Shakaib, S.M.F. Hasani, I. Ahmed, R.M. Yunus, A CFD study on the effect of spacer orientation on temperature polarization in membrane distillation modules, Desalination, 284 (2012) 332-340.

[55] M. Shakaib, S.M.F. Hasani, M. Ehtesham-ul Haque, I. Ahmed, R.M. Yunus, A CFD study of heat transfer through spacer channels of membrane distillation modules, Desalination and Water Treatment, 51 (2013) 3662-3674.

[56] A. Ali, F. Macedonio, E. Drioli, S. Aljlild, O.A. Alharbi, Experimental and theoretical evaluation of temperature polarization phenomenon in direct contact membrane distillation, Chem. Eng. Res. Des., 91 (2013) 1966-1197.

[57] A. Tamburini, G. Micale, M. Ciofalo, A. Cipollina, Experimental analysis via Thermochromic Liquid Crystals of the temperature local distribution in Membrane Distillation modules, Chem. Eng. Trans., 32 (2013) 2041-2046.

[58] A. Tamburini, P. Pitò, A. Cipollina, G. Micale, M. Ciofalo, A Thermochromic Liquid Crystals image analysis technique to investigate temperature polarization in spacer-filled channels for membrane distillation, J. Membr. Sci., 447 (2013) 260-273.

[59] A. Tamburini, L. Gentile, A. Cipollina, G. Micale, A. Brucato, Experimental investigation of dilute solid-liquid suspension in an unbaffled stirred vessels by a novel pulsed laser based image analysis technique, Chemical Engineering Transactions, 17 (2009) 531-536.

[60] A. Tamburini, A. Cipollina, G. Micale, A. Brucato, Particle distribution in dilute solid liquid unbaffled tanks via a novel laser sheet and image analysis based technique, Chem. Eng. Sci., 87 (2013) 341-358.

[61] R. Wiberg, N. Lior, Temperature measurements using thermochromic liquid crystals, Journal of Heat Transfer, 126 (2004) 503-504. 
[62] N. Abdullah, A.R. Abu Talib, A.A. Jaafar, M.A.M. Salleh, The basics and issues of Thermochromic Liquid Crystal Calibrations, Experimental Thermal and Fluid Science, 34 (2010) 1089-1121.

[63] L. Martínez-Diez, J.M. Rodríguez-Maroto, Effects of membrane and module design improvements on flux in direct contact membrane distillation, Desalination, 205 (2007) 97-103.

[64] L. Gurreri, A. Tamburini, A. Cipollina, G. Micale, M. Ciofalo, CFD prediction of concentration polarization phenomena in spacer-filled channels for reverse electrodialysis, J. Membr. Sci., 468 (2014) 133-148. 